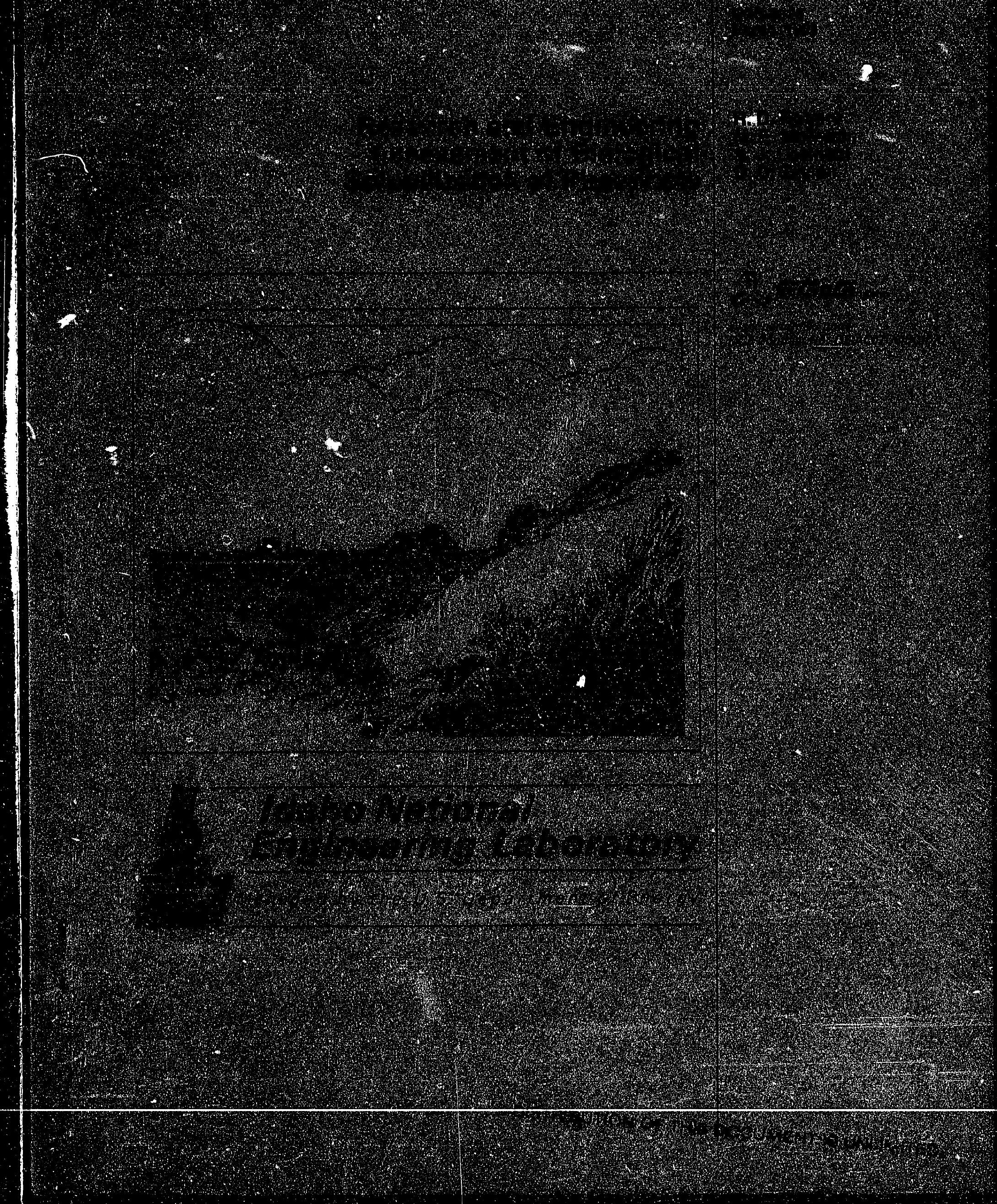




\section{8}

.

-

-

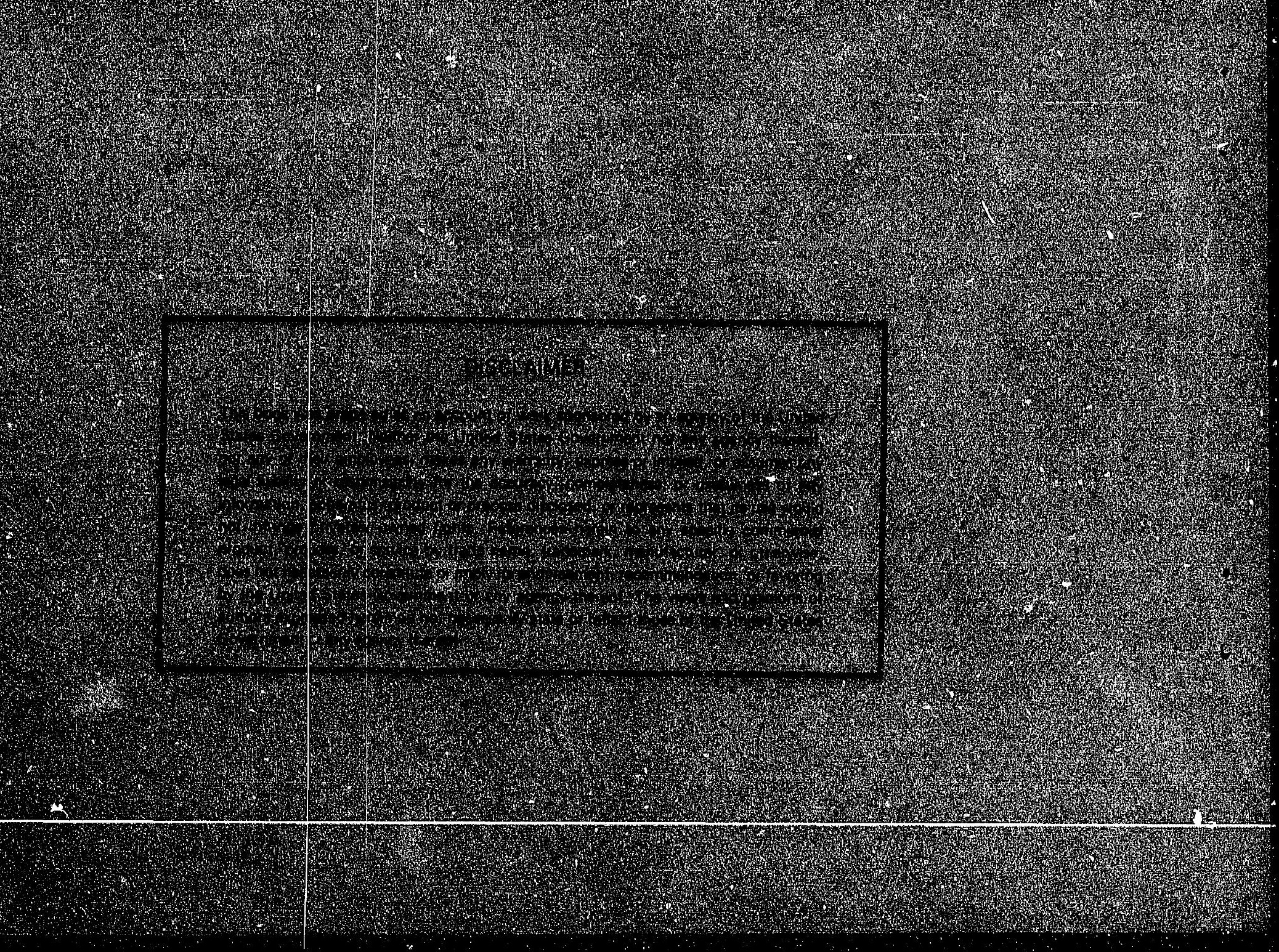




\title{
Research and Engineering Assessment of Biological Solubilization of Phosphate
}

\author{
R. D. Rogers \\ M. E. Mcllwain \\ S. J. Losinski \\ D. D. Taylor
}

Published March 1993

Idaho National Engineering Laboratory

EG\&G Idaho, Inc.

Idaho Falls, Idaho 83415

Prepared for the

U.S. Department of Energy

Assistant Secretary for Conservation

and Renewable Energy

Under DOE Idaho Field Office

Contract DE-AC07-76ID01570

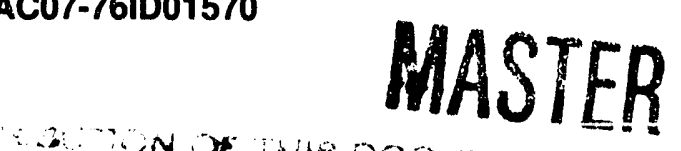




\begin{abstract}
This research and engineering assessment examined a microbial phosphate solubilization process as a method of recovering phosphate from phosphorus containing ore compared to the existing wet acid and electric arc methods. This activity was initiated in 1987 as an element of the Office of Conservation and Renewable Energy's Energy Conservation and Utilization Technology Program and has been supported by the public sector for its duration. A total of 860 microbial isolates, collected from a range of natural environments were tested for their ability to solubilize phosphate from rock phosphate. Based on this screening of microorganisms, a bacterium (Pseudomonas cepacia) was selected for extensive characterization and evaluation of the mechanism of phosphate solubilization and of process engineering parameters necessary to recover phosphate from rock phosphate. These studies found that concentration of hydrogen ion and production of organic acids arising from oxidation of the carbon source facilitated microbial solubilization of both pure chemical insoluble phosphate compounds and phosphate rock. Genetic studies found that phosphate solubilization was linked to an enzyme system (glucose dehydrogenase). Process-related studies found that a critical solids density of $1 \%$ by weight (ore to liquid) was necessary for optimal solubilization. An engineering analysis evaluated the cost and energy requirements for a 2 million ton per year sized plant, whose size was selected to be comparable to existing wet acid plants. The water handling and holding requirements made the conceptual bioprocess plant uneconomical. An optimized process was postulated based on increasing soluble phosphate concentration from $200 \mathrm{mg} / \mathrm{L}$ to $20,000 \mathrm{mg} / \mathrm{L}$. The optimized process was shown to be feasible and comparable in energy consumption to that of the wet acid process. It was considerably less energy intensive when compared to the oxidation method. Based on the findings of this study, a research plan was developed for future phosphate solubilization research.
\end{abstract}





\section{EXECUTIVE SUMMARY}

Phosphorus is an important element that is widely used in agriculture, chemical, and food industries. Depending on the method employed to recover phosphorus in the form of phosphate from mineral ore, a significant amount of energy ( 0.27 to 0.39 quads per year) is required to produce U.S. phosphate. Given the age of the technology currently being employed for recovery of phosphorus and the rapid depletion of economically viable domestic ore deposits, substantial improvements in the current technology base are required to expand viable resources and to maintain domestic industrial competitiveness.

The phosphate industry and other private companies are intrigued by the potential to employ microbial processes to release insoluble phosphate from a range of ore types. Microbial processes are often characterized as having low yields, slow rates, and dilute products. These characteristics are seen by industry as significant risks and hurdles to commercialization. To overcome these hurdles, industry has actively supported the research described in this assessment both by direct contribution and in-kind support.

Phosphate is a required nutrient for living systems. Microbial action appears to be one of the important mechanisms in the release of insoluble phosphate from soil. A wide range of soil microorganisms are reported to have an ability to cause phosphate release. When known phosphate solubilizing organisms are grown in the presence of a complex carbon source (i.e., glucose), hydrogen ions and organic acids are produced, which are considered to have a role in phosphate solubilization.

Based on available data, the potential for using microorganisms as a process methodology for phosphate recovery was investigated. Approximately 860 microbial isolates, including both bacteria and fungi, were tested for their ability to release insoluble phosphate from pure chemical insoluble phosphate compounds and rock phosphate (RP). The results of this evaluation found that more than one of the organisms tested had some ability to release phosphate. A strain of Pseudomonas cepacia was selected for its optimal ability to release phosphate from RP and for its ease of handling. This bacterium was characterized as to its mechanism of phosphate solubilization, growth and environmental requirements necessary for optimal solubilization, and process design and operation parameters required to create a functional bioprocess.

Studies that determined the growth and environmental properties of the bacterium showed that it could grow on a range of carbon sources, needed only the addition of trace metals as required nutrients, and required only gentle aeration for rapid growth. Certain carbon sources, specifically sugars and alcohols, were found to promote phosphate solubilization. When glucose was used as a representative carbon source, the concentration needed for solubilization to occur was determined to be between 0.25 and $1.0 \%$ by w/w. A $1 \%$ glucose concentration was shown to be an optimal concentration value, since increasing glucose concentration did not produce an increase in the rate of phosphate solubilization. Growth of $P$. cepacia on glucose resulted in immediate reduction of growth medium $\mathrm{pH}$. The optimum $\mathrm{pH}$ value for growth of the organism and solubilization of RP was $\mathrm{pH}$ 3.4. Gluconic and 2-ketogluconic acids were found to be present in the growth medium at concentrations proportional to glucose concentration. Adding these acids to RP in acidic ( $\mathrm{pH} 3.4$ ) solution produced phosphate solubilization. However, greater phosphate solubilization occurred when $P$. cepacia was present. This finding suggested that $P$. cepacia provided an additional function for phosphate solubilization other than synthesis of organic acids.

A collaborative effort between the Idaho National Engineering Laboratory (INEL) and Dr. A. Goldstein at California State University at Los Angeles was initiated to understand the mechanisms of phosphate solubilization. Calcium ion, hydrogen ion, and organic acids were shown to play key roles in the solubilization of phosphate from RP. Comparison studies to define the 
role of each of these species found that they functioned in concert in the presence of $P$. cepacia to cause optimal phosphate release.

Genetic studies showed that an inducible enzyme complex, glucose dehydrogenase, was responsible for phosphate solubilization. One protein of the enzyme complex was not present in nonsolubilizing bacteria. When the gene coding for the production of this protein was transferred to nonsolubilizing bacteria, the ability to solubilize phosphate was produced. Mutation experiments produced a number of mutants that had enhanced enzyme complex production. These mutants were not investigated for enhanced solubilization.

Results of process-related studies provided valuable information concerning process design and process operational parameters. A separate bioreactor was required for bacterial growth and production of lixiviant. A relatively unsophisticated bioreactor satisfied this need. This bioreactor could be mechanically or hydrodynamically stirred. $\mathrm{pH}$ control was found to be necessary for achieving high cell densities, carbon use, and organic acid production. $\mathrm{pH}$ control was accomplished by adding predetermined amounts of base. A stirred tank contactor was used to contact lixiviant with RP. It was selected because of its simplicity, phosphate yield, and availability of design data from the existing wet acid process. Excluding air or oxygen from the contactor was shown to be necessary for $\mathrm{pH}$ stability and high phosphate release. Phosphate solubilization was enhanced by high lixiviant flow rate through the contactor. These flow rates required either a solids settler or cyclone clarifier to capture washedout materials. Some form of calcium management was necessary to enhance the concentration of soluble phosphate. Without calcium ion removal, soluble phosphate concentration produced by contact with the lixiviant was approximately $200 \mathrm{mg} / \mathrm{L}$. Soluble phosphate concentration as high as $2,000 \mathrm{mg} / \mathrm{L}$ occurred when ion exchange resin beads were added to the lixiviant and RP. Finally, product recovery was shown to be possible using lime as a precipitation agent.
Operational process parameters in terms of current state-of-the-art bioprocess were detailed. Optimal glucose concentrition was shown to be $1 \%$ or $10 \mathrm{~g} / \mathrm{L}$. Soluble phosphate concentration without calcium ion management was consistently found to be approximately $200 \mathrm{mg} / \mathrm{L}$. Calcium ion removal was shown to potentially raise soluble phosphate concentration. $1 \mathrm{~g} / \mathrm{L}$ of lime was required to precipitate dicalcium phosphate dihydrate from a $200 \mathrm{mg} / \mathrm{L}$ soluble phosphate containing stream.

Using the above design and process parameters, a conceptual bioprocess was developed to process $1.8 \times 10^{9} \mathrm{~g}$ ( 2 million tons) of ore per year. A mass balance calculation for this conceptual bioprocess found that an enormous amount of water was necessary to operate the process. This amount of water required the water handling and holding equipment to be larger than any known process. This large water requirement was directly linked to the concentration of soluble phosphate. Since soluble phosphate concentration could be increased by calcium ion management, an optimized bioprocess was developed that increased soluble phosphate in the process streams to $20,000 \mathrm{mg} / \mathrm{L}$. Mass balance calculations showed that the optimized bioprocess substantially reduced the water requirements. Reduced water requirements also substantially changed the handling and holding requirements to create an economic process. For the optimized bioprocess, capital equipment costs were estimated to be approximately $\$ 69$ million. The total fixed capital cost for the plant was estimated to be roughly $\$ 318$ million. Further, the bioprocess was estimated to use more energy than the existing wet acid process $(3,700 \mathrm{Btu} / \mathrm{lb})$ by approximately $162 \mathrm{Btu} / \mathrm{lb}$ of ore. The bioprocess was considerably more efficient $(3,887 \mathrm{Btu} / \mathrm{lb})$ than the oxidatir a method $(7,750 \mathrm{Btu} / \mathrm{lb})$.

Based on the engineering analysis, four critical hurdles for the current state-of-the-art bioprocess are apparent. Research and engineering efforts need to overcome these hurdles in order to have a viable bioprocess. These critical hurdles are: 
- Soluble phosphate concentration of at least $20,000 \mathrm{mg} / \mathrm{L}$ was necessary for a viable bioprocess.

- Reduction of the number of separations was needed to reduce both capital equipment costs and energy consumption.

- Grinding of the ore to a fine size for either the bioprocess or wet acid process represented a major energy consuming unit operation. Using a larger grind size was recommended.

- Sterilization of process streams represented a major energy consumption.

As a result of this research and engineering analysis, a research plan is suggested to direct near-term research and process development efforts. This research plan focuses on increasing the soluble phosphate concentration by a factor of 100. This critical hurdle is addressed, because without this improvement the bioprocess is not feasible. Further, research results suggest that attaining the required level of soluble phosphate is possible through calcium ion management and genetic metabolic engineering of the organism. Remaining critical hurdles can be the subject of a longer term research effort.

In summary, biological solubilization of RP has been shown. Increased understanding of the mechanism by which P. cepacia causes phosphate solubilization has been gained. Process design and operational parameters have been suggested. Based on an optimized bioprocess where soluble phosphate has been evaluated, mass balance calculations, capital costs, and energy consumption have been estimated. Four critical hurdles have been presented and must be overcome for a viable bioprocess. A research plan has been developed to overcome the most substantial of these hurdles, soluble phosphate concentration. If this hurdle is overcome, a cost competitive, energy efficient bioprocess is realizable in relation to the existing wet acid process. If all hurdles are overcome, the resulting bioprocess will have a lower product cost and substantial energy savings, compared to existing phosphate recovery processes. 


\section{CONTENTS}

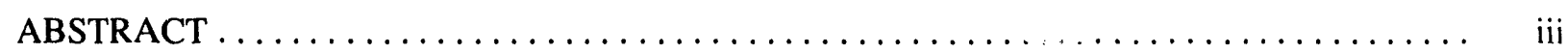

EXECUTIVE SUMMARY $\ldots \ldots \ldots \ldots \ldots \ldots \ldots \ldots \ldots \ldots \ldots \ldots \ldots \ldots \ldots$

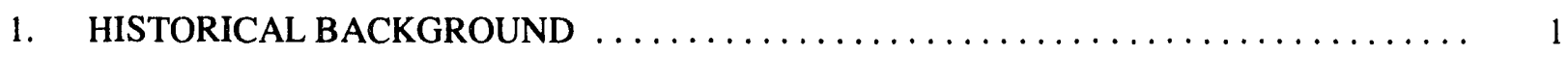

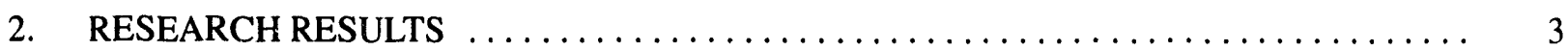

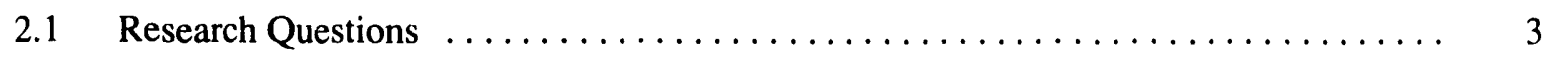

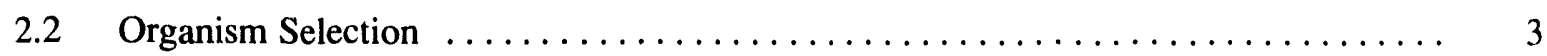

2.3 Mechanism of Phosphate Solubilization $\ldots \ldots \ldots \ldots \ldots \ldots \ldots \ldots \ldots \ldots$

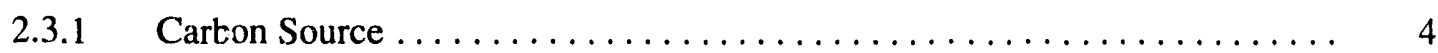

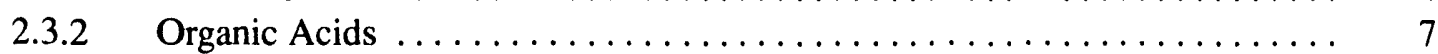

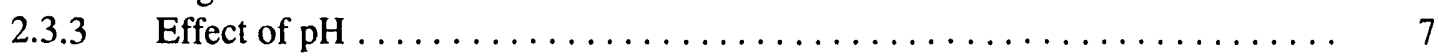

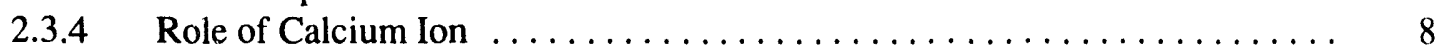

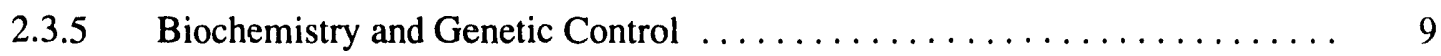

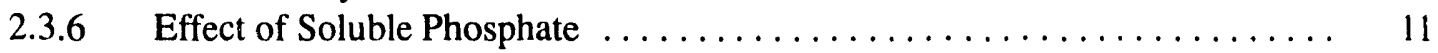

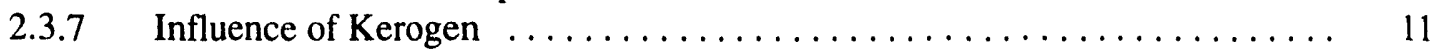

2.3.8 Postulated Mechanisms for Bacterial Solubilization $\ldots \ldots \ldots \ldots \ldots \ldots \ldots 12$

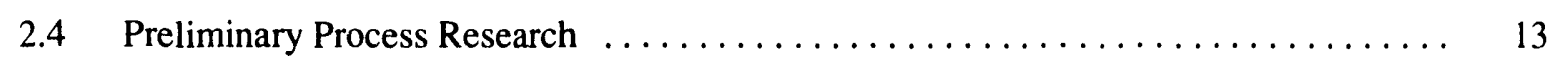

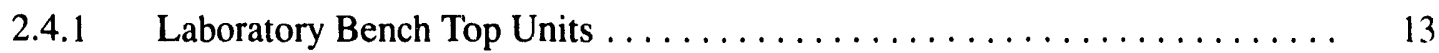

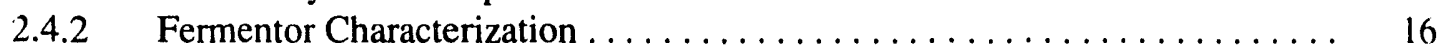

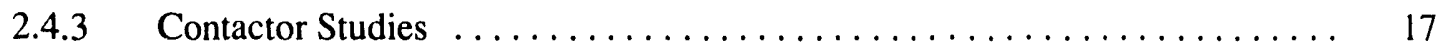

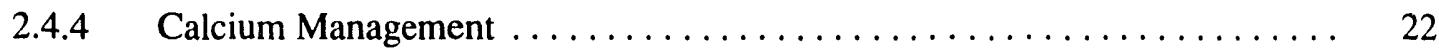

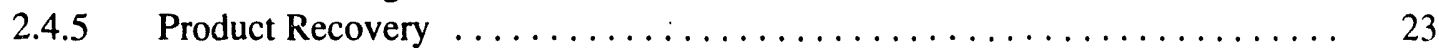

2.4.6 Summary of Process Data $\ldots \ldots \ldots \ldots \ldots \ldots \ldots \ldots \ldots \ldots \ldots \ldots \ldots \ldots \ldots \ldots \ldots$

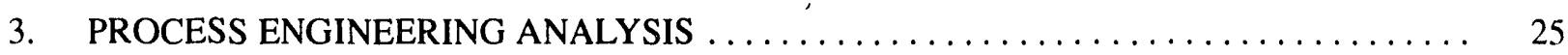

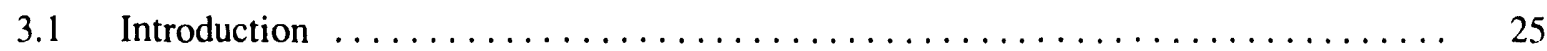

3.2 Process Flow Diagram for Bioprocesss $\ldots \ldots \ldots \ldots \ldots \ldots \ldots \ldots \ldots \ldots \ldots \ldots \ldots \ldots \ldots \ldots$

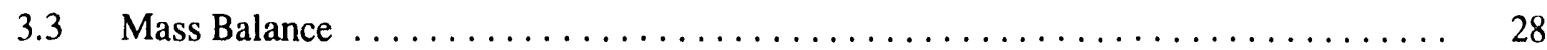

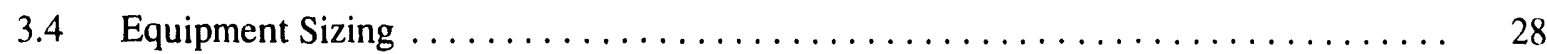

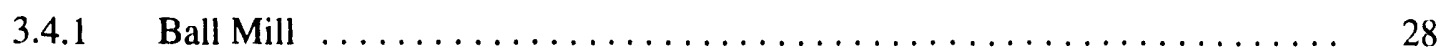

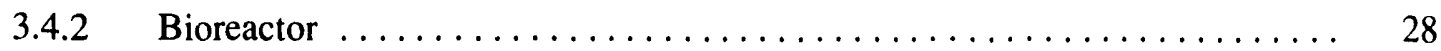

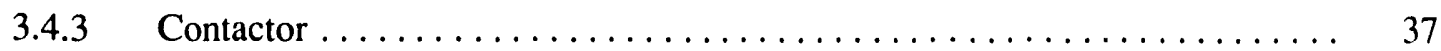

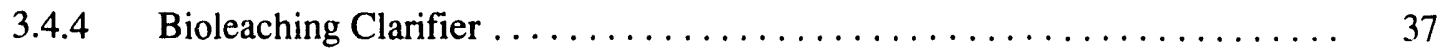

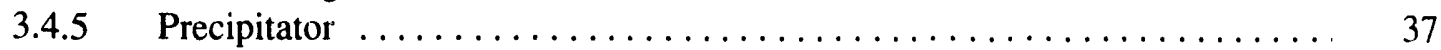

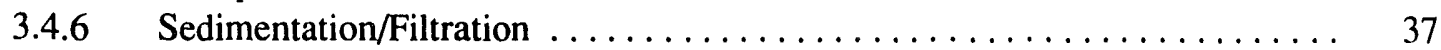

$3.4 .7 \quad$ Calcium Removal $\ldots \ldots \ldots \ldots \ldots \ldots \ldots \ldots \ldots \ldots \ldots \ldots \ldots$ 
3.4.8 $\quad \mathrm{pH}$ Adjustment Contactor $\ldots \ldots \ldots \ldots \ldots \ldots \ldots \ldots \ldots \ldots \ldots \ldots \ldots \ldots \ldots \ldots \ldots$

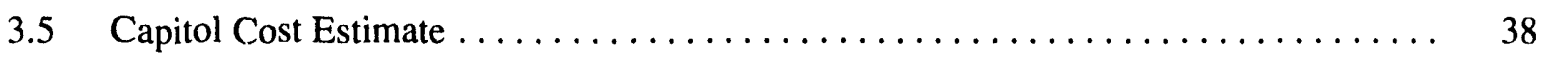

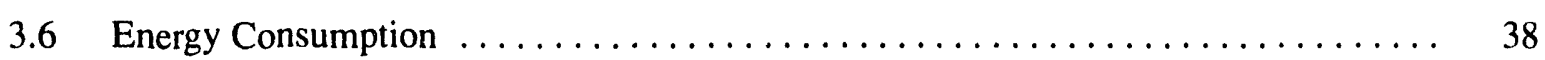

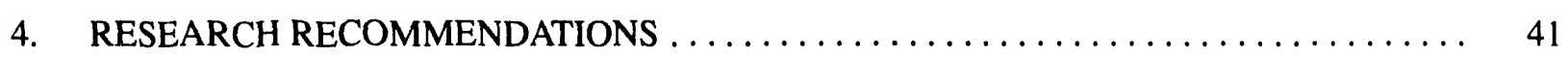

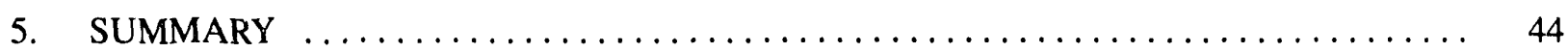

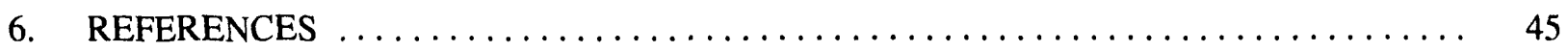

\section{FIGURES}

1. Phosphate solubilized by Day 6 versus glucose concentration $\ldots \ldots \ldots \ldots \ldots \ldots \ldots$

2. Quantity of phosphate solubilized from RP in contact reactor with and without $\mathrm{H}$-form cation exchange resin. Note: $1 \mathrm{mEq}=32 \mathrm{mg} / \mathrm{L} \ldots \ldots \ldots \ldots \ldots \ldots$

3. Flow diagram for phosphoric acid wet process $\ldots \ldots \ldots \ldots \ldots \ldots \ldots \ldots \ldots \ldots \ldots$

4. Flow diagram for conceptual biosolubilization process $\ldots \ldots \ldots \ldots \ldots \ldots \ldots \ldots \ldots$

5. Schematic of process for continuous biosolubilization of RP $\ldots \ldots \ldots \ldots \ldots \ldots \ldots \ldots$

6. Glucose analysis of lixiviant from utility bioreactors over time for recycle

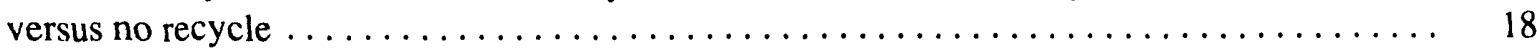

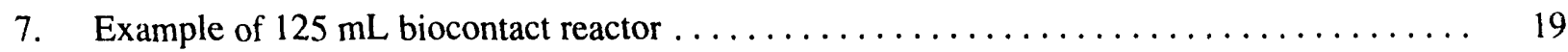

8. Process flow sheet for conceptual biosolubilization process $\ldots \ldots \ldots \ldots \ldots \ldots \ldots \ldots .27$

\section{TABLES}

1. General classification of phosphate solubilizing bacteria $\ldots \ldots \ldots \ldots \ldots \ldots \ldots \ldots \ldots$

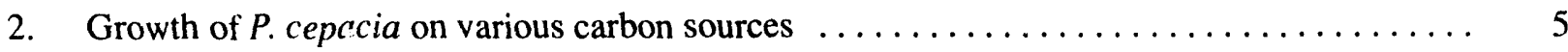

3. Comparison of microbial growth and phosphate solubilization by $P$. cepacia

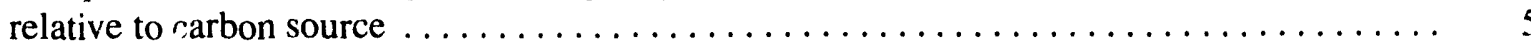

4. Titratable acidity and organic acid produced by P. cepacia in media amended with $1 \%$ ethanol. Organic acid identified as oxalic acid $\ldots \ldots \ldots \ldots \ldots \ldots \ldots \ldots$

5. Continuous leaching of phosphate from various amounts of RP as a function of

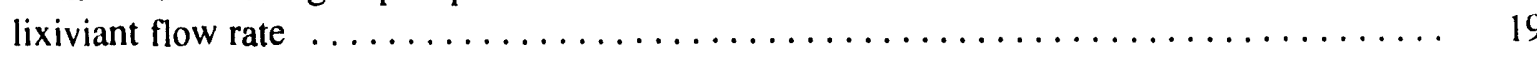

6. Mass balance for bioleaching of rock phosphate ore based on assumed process

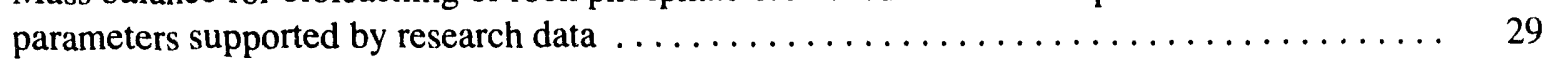

7. Mass balance for bioleaching of rock phosphate ore: optimized process $\ldots \ldots \ldots \ldots \ldots \ldots$ 
8. Factors used to prepare fixed capital cost estimate $\ldots \ldots \ldots \ldots \ldots \ldots \ldots \ldots \ldots \ldots \ldots \ldots$

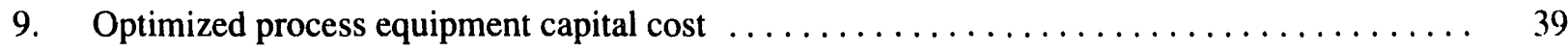

10. Bioprocess operation energy consumption estimate $\ldots \ldots \ldots \ldots \ldots \ldots \ldots \ldots \ldots \ldots$

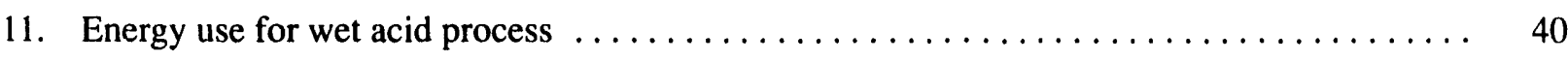

12. Energy use for oxidation method process $\ldots \ldots \ldots \ldots \ldots \ldots \ldots \ldots \ldots \ldots \ldots \ldots$ 


\section{Research and Engineering Assessment of Biological Solubilization of Phosphate}

\section{HISTORICAL BACKGROUND}

The activities detailed within the research results portion of this assessment were initiated in 1987 and are a part of the Conservation and Renewable Energy (CE)-Energy Conservation and Utilization Technology program's Biocatalysis Project. The intent of this CE program is to support research and devciopment activities that hindered commercialization of bioprocesses. Biological processes, such as microbial solubilization of phosphate, have generic problems: low rates of conversion, low product yields, and dilute product streams, and these problems are significant hurdles relative to private sector investment for commercialization.

The merit and potential gain represented by microbial processes for phosphate solubilization have been such that private support for this program, both in direct and inkind contributions, have been present since its inception. After 5 years and $\$ 1.27$ million of CE funds and $\$ 180$ thousand of private investment, the concept has reached sufficient development that the private sector is satisfied that technical barriers can be crossed and is serious about development of a commercial process. A Cooperative Research and Development Agreement partnership between J. R. Simplot Company and the Idaho National Engineering Laboratory (INEL) is seeking to develop the phosphate manufacturing process. Other private concerns are working to apply the INEL technology to other applications. Cleveland Cliffs Iron Company is interested in using the process to upgrade iron ore. Dupont has interest in using the process to remove phosphate from other ore. The strong industry support for this technology represents their desire to commercialize the technology and serves as a driving factor for these activities.

Phosphorus (in the form of phosphoric acid, ammonium phosphate, dicalcium phosphate, and elemental phosphorus) is widely used in agricul- ture, chemical, and food industries. Phosphates used in these industries are not recoverable, and must be continually generated. Once phosphate anions enter the environment, they become immobilized because of the chemical and biological reactions. Phosphate is produced from sedimentary deposits rich (greater than $26 \%$ ) in mineral phosphate $\left(\mathrm{P}_{2} \mathrm{O}_{5}\right)$. Depending on the method of phosphate recovery, separating phosphate from phosphate bearing rock requires significant amounts of energy ( 0.27 to 0.39 quads per year depending on the recovery process are expended to process approximately $18 \times 10^{9} \mathrm{~g}$ (20 million tons of ore). Thus only the richest deposits are amenable to current recovery technology. Recovery methods have not radically changed since the turn of the century. The industry and nation need a new technology that has the potential to reduce process energy consumption and minimize waste production. Given that domestic phosphate deposits are rapidly being depleted, either substantial improvements in current processing technology or the development of a new, energy conservative method is needed to expand usable reserves of phosphate ore. If these developments are achieved, they will also enhance domestic industrial competitiveness.

Phosphate is a required nutrient for all living systems. In natural settings phosphate must be recovered from soil to provide metabolic phosphate for org nism growth. Microbial action appears to be oule of the important mechanisms in the release of insoluble phosphate from soil. ${ }^{1}$ In the laboratory, bacteria and fungi produce scluble phosphate from various types of insoluble phosphate containing compounds.

Microbial solubilization of phosphate was demonstrated when plants grown in the presence of certain soil microorganisms were observed to dramatically increase the uptake of phosphate. Increased phosphate uptake was linked to increased solubility. ${ }^{1-10}$ Additional research has 
shown that selected soil microorganisms can solubilize phosphate from a range of phosphate bearing materials, such as dicalcium phosphate, tricalcium phosphate (TCP), hydroxyapatite, basic slag, and rock phosphate (RP). ${ }^{2}$ These microorganisms were able to release as much as $50 \%$ of the di- and TCP and 1 to $33 \%$ from the more refractory forms of phosphate containing materials.

Many different soil microorganisms were reported to have an ability to cause phosphate solubilization including bacteria, fungi, and actinomycetes..$^{3-8}$ All organisms found to solubilize phosphate required the addition of a complex carbon nutrient to facilitate increased phosphate solubilization. Two mechanisms were suggested to describe the microbial solubilization process: (1) generation of organic acids and (2) production of calcium chelating agents. When known phosphate solubilizing organisms were grown in the presence of an appropriate carbon source, such as glucose, organic acids including lactic, glycolic, citric, succinic, and 2-ketogluconic acids were identified in the growth solution. One mechanism suggested that organic acids interact with insolu- ble phosphate in a similar manner to inorganic acids. However, an analysis of the influence of growth medium $\mathrm{pH}$ on solubilization did not show a correlation. A second mechanism suggested phosphate release was related to chelation of calcium by organic acids. Replacement of dissociated calcium and hydrogen ions was considered to promote solubilization of phosphate.

The ability of microorganisms to solubilize phosphate appeared to be genetically controlled in at least one species of bacteria. ${ }^{9}$ When genetic material was removed from a bacterium able to promote phosphate solubilization and transferred to a nonsolubilizing bacterium, the nonsolubilizing bacterium was then found to actively solubilize. A feedback mechanism appeared to be present in this organism. When the bacterium was grown in the presence of orthophosphate, solubilization of the insoluble phosphate compound proceeded until the concentration exceeded $100 \mathrm{mg} / \mathrm{L}$; then solubilization ceased. Based on the results for this bacterium, phosphate inhibited the production of the solubilization agent. The site of inhibition was not determined, nor was a change in organic acid production noted. 


\section{RESEARCH RESULTS}

\subsection{Research Questions}

The following questions were raised during research on microbial solubilization of phosphate containing materials and phosphate rock:

- Since the ability to release phosphate had been shown for a number of microbes, how diverse in the microbial world is the ability to solubilize phosphate?

- $\quad$ Several postulated mechanisms for microbial solubilization have been suggested. Can a better understanding of this mechanism be obtained?

- If a mechanism can be identified, can alteration of the organisms' growth conditions, genetic character, and/or properties of the substrate lead to improved solubilization?

- Organic acids, hydrogen ion, and calcium chelation have been identified as being important for microbial solubilization. What is the relationship of these variables relative to the amount of phosphate in the leachate?

- Are extracellular enzymes involved in solubilization?

- Is direct contact of microbes with the rock required for solubilization to occur or are their metabolic products causing solubilization?

- A soluble phosphate concentration of $200 \mathrm{mg} / \mathrm{L}$ appears to be the upper limit for free phosphate. Can a microbial process be developed to concentrate the phosphate or to overcome this limiting concentration?

- Can free phosphate be recovered or concentrated?
- Are the genetics of the selected organism amenable to modification so that enhanced solubilization can be obtained?

- What nutrient carbon sources can be used to promote solubilization?

- Given that organic material is present in the phosphate rock as kerogen, what is its influence on phosphate solubilization?

- What is the optimum rate of phosphate solubilization?

- Is the process by which the microbe or the microbial produced solution combines with the rock important in relation to the amount of phosphate release?

- Given that solubilization can be reproducibly demonstrated in batch experiments, can a continuous process be developed?

- What type(s) of unit operations are necessary to create a microbial phosphate solubilization process? What unit operations are needed to make the bioprocess optimal?

- How sensitive is the biosolubilization process to contamination by nonphosphate solubilizing microbes?

- What is the optimal phosphate rock slurry density?

- What is the role of calcium ion, and how can its concentration be controlled?

The following sections attempt to address these questions.

\subsection{Organism Selection}

Based on the literature, numerous soil microorganisms are known to promote phosphate solubilization. Data suggest that certain fungi are better solubilizers in relation to bacteria; however, broad screening of a large number of 
organisms has not been performed. It is uncertain whether the solubilization of phosphate is a unique genetic trait or homogeneous to the soil microbial population.

The initial task of this research was to better characterize the solubilization trait in the soil microbial community. Agar plate bioassay (a simple, rapid screening procedure) for screening large numbers of microorganisms was developed. ${ }^{10}$ The agar was prepared with a carbon substrate (glucose), minimal salts, and TCP. The uninocculated plates were opaque to light transmission because of the presence of undissolved TCP. Clearing of the plate by solubilization of the TCP indicated phosphate solubilization ability. Relative ability to solubilize TCP was estimated by the size of the clear halo in relation to the colony size.

Eight hundred and sixty microbial isolates were collected from 54 different environmental settings (including phosphate mining and processing sites) and were screened for solubilization activity. Approximately one-third of these organisms were found to have an ability to solubilize TCP; $36 \%$ of the bacteria and $19 \%$ of the fungi were able to be solubilized. Phylogenic characterization of the fungi indicated that they were generally Penicillium. However, representatives of Aspergillus, Acremonium, Verticillium, Geoyces, and Chrysosporium were also identified. Rough characterization of the bacteria, based on cell morphology and gram stain character, was performed (see Table 1). Results of this diversity study confirmed reports that ability to solubilize phosphate was widely distributed in nine soil microbial populations. Based on the data

Table 1. General classification of phosphate solubilizing bacteria.

Organism type Percent occurrence

\begin{tabular}{lr} 
Gram negative rods & 56 \\
Gram positive rods & 11 \\
Gram positive cocci & 4 \\
Gram negative cocci & 9 \\
\hline
\end{tabular}

obtained, bacterial and nine fungal isolates were evaluated for growth in broth culture.

The liquid culture medium was prepared using $1 \%$ glucose, minimal salts, and phosphate from either TCP or RP ore. Four isolates, A562, A9, E37, and I5G, were found to optimally solubilize TCP. A similar set of experiments were conducted with $100 \mathrm{mg}$ of RP added to the minimal broth as the phosphate source (phosphorus accounted for approximately $13.7 \%$ by weight of the RP). The same four solubilizing organisms were the same as found for TCP. Phosphate solubilized ranged from $10-71 \%$. The amount of RP solubilized in these experiments exceeded reported values. If the contact time was extended to 21 days, as much as $80 \%$ of the RP available phosphorus was released as phosphate.

Based on the results of the TCP and RP broth studies, two organisms (a bacterium, Pseudomonas cepacia and a fungus, Penicillium funiculosum) were considered for additional characterization studies. Based on difficulty with growing the fungus in continuous bioreactors, the bacterium was chosen for further bioreactor studies because of its ease of use.

\subsection{Mechanism of Phosphate Solubilization}

Two mechanisms had been proposed to explain how microorganisms solubilized phosphate. Both mechanisms suggested that organic acids derived from complex carbon sources, hydrogen ion, calcium, and concentration of phosphate ion were important elements or controlling factors in the bioprocess. Research activities were focused on determining the role of each of these factors in the solubilization of phosphate.

2.3.1 Carbon Source. Initial screening studies had shown that $P$. cepacia was capable of growth and RP solubilization when grown in a broth medium containing glucose as the carbon source. It was unknown whether these organisms could use other carbon sources. Growth on carbon sources other than glucose was used to determine: (a) role of organic acids in phosphate solubilization and (b) whether the nutrient carbon sources 
influenced solubilization. To test the growth and dependence of carbon source on solubilization, 15 carbon sources were selected and evaluated. These carbon sources included lactate, citrate, glycerol, ethanol, palmitate, D-gluconate, xylose, glycine, sucrose, mannitol, sorbose, fructose, galactose, glutamate, and glucose. A preliminary determination ascertained which of these compounds supported growth. The growth medium contained either $1 \%$ carbon source or $0.1 \%$ (in the case of lactate and glycerol), minimal salts, and soluble phosphate. Growth was determined using turbidity and change in medium $\mathrm{pH}$. Table 2 indicates the results of these experiments. P. cepacia grew on all compounds except citrate, glycine, and sorbose. $P$. cepacia growing on organic acids produced either slightly acidic $(>\mathrm{pH} 6)$ or alkaline $(>\mathrm{pH} 7)$ media. When grown on alcohol or sugar, the bacterium produced strongly acidic media. This preliminary study confirms that a range of carbon sources will support growth of these phosphate solubilizing organisms.

Table 2. Growth of P. cepacia on various carbon sources.

\begin{tabular}{lcc}
\hline Substrate & Growth & Soln pH \\
\cline { 2 - 3 } Lactate & + & 7.62 \\
Glycerol & ++ & 4.52 \\
Ethanol & + & 4.30 \\
Palmitate & + & 6.45 \\
Gluconate & +++ & 8.32 \\
Citrate & - & 7.06 \\
Xylose & ++ & 3.43 \\
Glycine & - & 7.06 \\
Sucrose & ++ & 3.78 \\
Mannitol & ++ & 3.96 \\
Sorbose & - & 6.73 \\
Fructose & ++ & 3.75 \\
Galactose & ++ & 3.53 \\
Glutamate & ++ & 8.86 \\
Glucose & ++ & 3.46 \\
& & \\
\hline \multicolumn{2}{l}{ Note: Growth given as a relative indication. $(-$, no } \\
growth, increasing number of + signs indicate \\
better growth.)
\end{tabular}

To determine if the carbon source had an influence on the extent of phosphate solubilization, lactate, glycerol, ethanol, palmitate, xylose, galactose, glutamate, and glucose were chosen. Gluconate was not used since it was produced by glucose metabolism. Glucose was used as a positive control. Experiments were conducted in $150-\mathrm{mL}$ shake flasks containing $50 \mathrm{~mL}$ of minimal salts medium amended with either $1 \%$ of the carbon source or $0.1 \%$ of lactate and glycerol and $100 \mathrm{mg}$ of RP. Following inoculation, the solubilization was allowed to proceed for 7 days. Daily samples were collected for analysis. Based on Day 7 soluble phosphate, at least $10 \%$ and as much as $53 \%$ of the available phosphate was removed from RP by growth on glucose, ethanol, gaiactose, and xylose. All other carbon sources yielded less that $10 \%$ (see Table 3 ).

Cell density of $P$. cepacia on various nutrient carbon sources was not correlated with RP solubilization. When cell density at various days following inoculation was used as a measure of growth, glucose afforded rapid increase in cell density during the first day followed by declining cell numbers in subsequent days. Ethanol, galactose, and xylose as nutrient carbon resulted in cell density to rise to Day 4 and decline thereafter. Glucose derived RP solubilization increased rapidly following inoculation and leveled off after a

Table 3. Comparison of microbial growth and phosphate solubilization by $P$. cepacia relative to carbon source.

\begin{tabular}{lccc}
\hline Carbon & $\begin{array}{c}\text { Cell } \\
\text { source }\end{array}$ & $\begin{array}{c}\text { Phosphate } \\
\text { solubilized } \\
(\%)\end{array}$ & $\begin{array}{c}\text { Day 7 } \\
\mathrm{pH}\end{array}$ \\
\hline Lactate & $1 \times 10^{8}$ & 0.2 & 8.9 \\
Glycerol & $1 \times 10^{9}$ & 3.7 & 5.9 \\
Ethanol & $1 \times 10^{8}$ & 10.9 & 4.4 \\
Palmitate & $1 \times 10^{8}$ & 1.0 & 7.5 \\
Xylose & $1 \times 10^{8}$ & 26.0 & 3.7 \\
Galactose & $1 \times 10^{7}$ & 53.0 & 3.5 \\
Glutamate & $1 \times 10^{9}$ & 0.6 & 8.7 \\
Glucose & $1 \times 10^{7}$ & 52.6 & 3.5 \\
\hline
\end{tabular}


few days. Other carbon sources caused RP solubilization to increase steadily until the termination of the experiment at Day 7. These findings implied that some factor(s) other than cell density was in part responsible for solubilization.

To further characterize the role of the carbon source for RP solubilization, $P$. cepacia was grown in a bioreactor where the growth conditions could be maintained. Lixiviant (biomass, organic acids, and spent growth media) from the bioreactor was transferred to contact reactors containing RP. Since glucose gave the highest solubilization, glucose was used as the carbon source. Experiments were performed to test various glucose concentrations on RP solubilization. Glucose concentration was varied between 0.1 and $2.5 \%$. Solubilization was determined by daily analysis of recovered lixiviant from the contact reactors.

The results of this study (see Figure 1) showed that the amount of solubilization correlated with the amount of carbon source provided to the microorganism. There was little or no solubilization for glucose concentration of $0.1 \%$. Onset of solubilization occurred at $0.25 \%$. Solubilization increased to a concentration of $1.0 \%$. Solubilization was not enhanced at $2.5 \%$ glucose when compared to that obtained for $1.0 \%$.

This finding implied that at the lowest concentration of glucose, all glucose was being used by the bacterium for metabolism. At glucose levels above $0.1 \%$, glucose oxidation occurred at a rate that exceeded metabolic requirements of $P$. cepacia. This resulted in solubilization of RP, and accumulation of gluconic acid in the media.

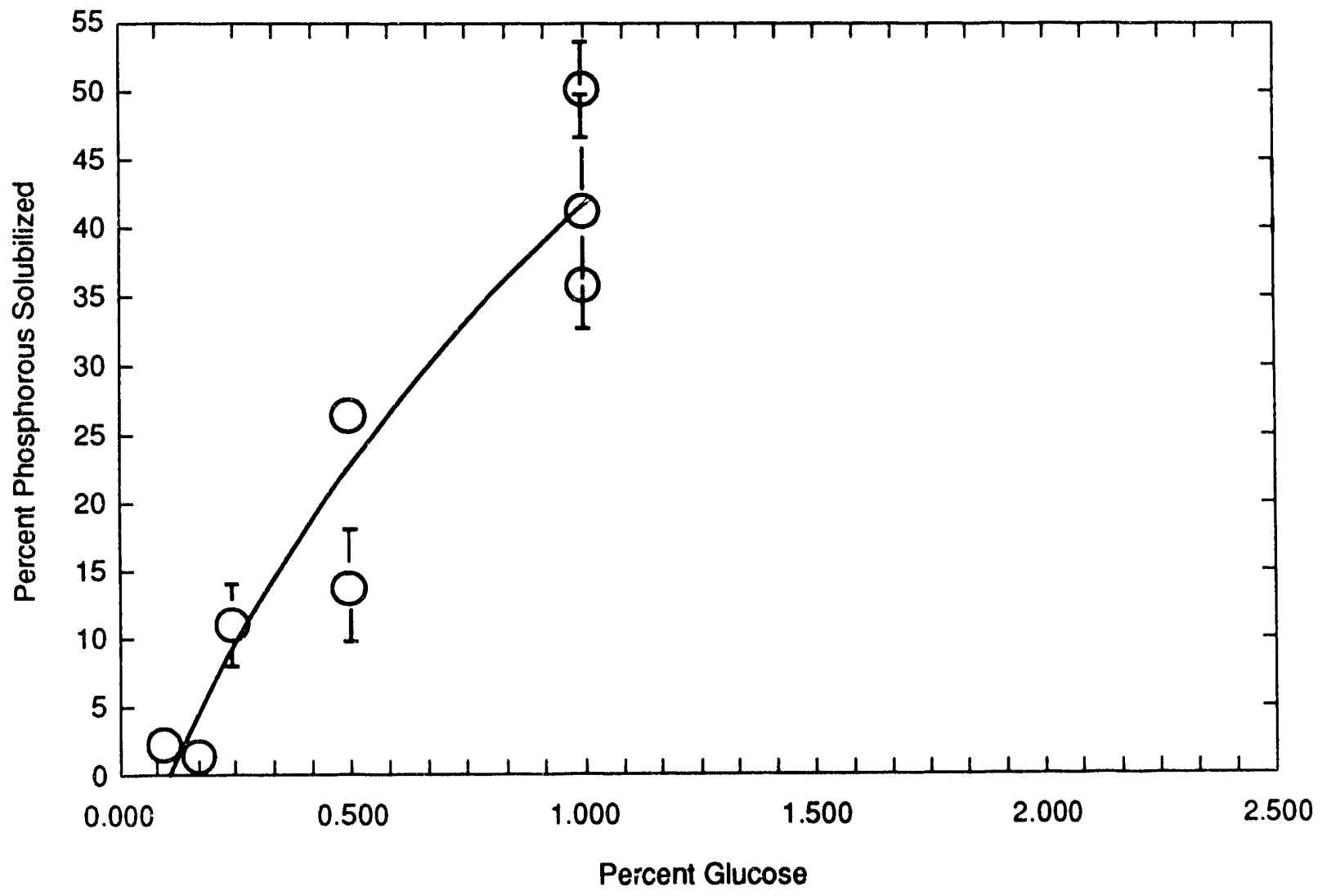

$\times 930013$

Figure 1. Phosphate solubilized by Day 6 versus glucose concentration. 
2.3.2 Organic Acids. Samples collected during the previously described study were analyzed using high-performance liquid chromatography for the presence of organic acids. Based on a companion technique development effort, two organic acids were deduced to predominate the organic acids released by these organisms. Gluconic acid and 2-ketogluconic acid were found to predominate.

When $P$. cepacia was grown on xylose, galactose, and ethanol, other organic acids were determined to be present in the supernate. These organic acids represent the carboxylic acid of the parent carbon substrate.

To determine if the presence of organic acid(s) could explain the observed phosphate solubilization occurring when the bacterium was present in the medium, an abiotic study was undertaken to determine the solubilizing capacity of organic acids without microorganisms. $P$. cepacia and glucose produced the best solubilization, and gluconic acid was the predominant acid produced. Gluconic acid was selected as the test acid. Five concentrations of gluconic acid were used: $0,0.1 \mathrm{mg} / \mathrm{L}, 0.5 \mathrm{mg} / \mathrm{L}$, $1.0 \mathrm{mg} / \mathrm{L} .5 .0 \mathrm{mg} / \mathrm{L}$. Leach solution was the same as that used for growth medium, except the microorganism was not introduced and the organic acid was added. The solutions containing $\mathrm{RP}$ with medium and controls were maintained at $\mathrm{pH}$ 4. This study showed that gluconic acid participated in the solubilization of RP. The degree of solubilization correlated with the amount of organic acid initially added to the medium. Between 28 and $53 \%$ of the RP was solubilized within 3 days. However, the solubilization did not seem to occur on a basis strictly equivalent to the amount of organic acid added. Similar results were obtained in abiotic leaching experiments when 2-ketogluconic acid replaced gluconic acids. The amount of solubilization was less than that obtained with similar concentrations of gluconic acid.

Thus, gluconic acid can be linked to phosphate solubilization. Further, the literature suggests that this acid and 2-ketogluconic acid are responsible for solubilization. When $P$. cepacia is grown on glucose, both acids are present and produced during metabolism. However, when the microorganism is grown on other carbon sources, gluconic and 2-ketogluconic acids are not predominantly formed; different organic acids are found. The concentration of organic acid is not well correlated to phosphate solubilization. These results suggest:

- Some organic acids may be better for phosphate solubilization

- Some other factor is participating with the organic acid to facilitate solubilization.

2.3.3 Effect of $\mathrm{pH}$. Previous results suggest that the concentration of hydrogen ion in the medium correlates to phosphate solubilization. Growth studies showed that when $P$. cepacia was grown on alcohol or sugar, the final medium had elevated levels of hydrogen ion or lower $\mathrm{pH}$ (see Table 2). RP solubilization studies further illustrated the importance of hydrogen ion, since in the case of the bacterium, high amounts of phosphate solubilization was accompanied by low $\mathrm{pH}$ values (see Table 3 ).

Other results suggest that the organic acids could chelate calcium ion. Free hydrogen ion could be generated by calcium chelation. The relationship between hydrogen ion concentration and organic acid was investigated for growth in ethanol. Results of these studies showed that elevated concentrations of hydrogen ion were present in the medium before the appearance of measurable amounts of organic acids (see Table 4). This study showed that organic acids were not the principal source of hydrogen ion.

Although the previous study showed that hydrogen ion was generated independently of organic acids, it did not give any information as to the role of hydrogen ion in the solubilization of phosphate. Abiotic studies using hydrochloric acid $(\mathrm{HCl})$ had shown that hydrogen ions could afford solubilization. However, studies comparing the amount of RP solubilized by mineral acid 
Table 4. Titratable acidity and organic acid produced by $P$. cepacia in medium amended with $1 \%$ ethanol. Organic acid identified as oxalic acid.

\begin{tabular}{lll}
\hline $\begin{array}{c}\text { Time } \\
(\mathrm{d})\end{array}$ & $\begin{array}{c}\text { Titratable acid } \\
(\mathrm{mEq})\end{array}$ & $\begin{array}{c}\text { Organic acid } \\
(\mathrm{mg} / \mathrm{L})\end{array}$ \\
\hline 0.25 & $0.14 \pm 0.01$ & None \\
1 & $0.15 \pm 0.01$ & None \\
2 & $0.18 \pm 0.01$ & None \\
3 & $0.26 \pm 0.01$ & $0.05 \pm 0.00$ \\
4 & $0.29 \pm 0.02$ & $0.03 \pm 0.00$ \\
5 & $0.32 \pm 0.05$ & $0.04 \pm 0.10$ \\
6 & $0.32 \pm 0.06$ & $0.12 \pm 0.10$ \\
7 & $0.27 \pm 0.06$ & $0.04 \pm 0.00$ \\
9 & $0.44 \pm 0.08$ & $0.03 \pm 0.00$ \\
11 & $0.55 \pm 0.05$ & None \\
15 & $0.60 \pm 0.00$ & $0.07 \pm 0.03$ \\
\hline
\end{tabular}

and the bacterium at similar hydrogen ion concentrations found that the microorganism solubilized more phosphate.

Most studies with the P. cepacia showed a lag time before solubilization occurred. Since the previously discussed study showed a lag time associated with production of organic acids, another set of abiotic experiments was performed to compare solubilization of RP in the presence of organic acids with varying amounts of hydrogen ion concentrations. In these experiments, several concentrations of gluconic acid were used, the $\mathrm{pH}$ of the acid was adjusted to 3.0 or buffered to 6.5 , and the resulting mixture allowed to contact RP. As a control, a solution of water adjusted to pH 3.5 with $\mathrm{HCl}$ was used. Following a contact time of 8 days, the solutions containing gluconic acid maintained at $\mathrm{pH} 3.0$ were shown to have produced more RP solubilization than acidified water. Further, the amount of phosphate solubilization was shown to be directly correlated to the concentration of gluconic acid. Thus, both hydrogen ion concentration and gluconic acid concentration are important, since the $\mathrm{pH} 6.5$ buffered gluconic acid containing solutions had significantly lower phosphate solubilization than those maintained at $\mathrm{pH} \mathrm{3}$. The amount of $\mathrm{pH} 6.5$ buffered gluconic acid solutions was less than that obtained for $\mathrm{pH} 3$ acidified water, but was greater than that solubilized by distilled water (which was $\mathrm{pH} 7$ ).

These results suggest that hydrogen ion concentration is important to facilitate phosphate solubilization. For abiotic experiments where $\mathrm{pH} 3.5$ and neutral water are compared, phosphate solubilization occurs at elevated hydrogen ion concentrations. The presence of an organic acid (gluconic or 2-ketogluconic) affords greater solubilization when hydrogen ion is high. Further, when similar concentrations of hydrogen ion are compared with and without the presence of organic acids, the presence of organic acid promotes increased solubilization.

2.3.4 Role of Calcium Ion. The insolubility of most compounds containing calcium, including calcium dihydrogen phosphate, suggests that calcium ion plays an important role in determining phosphate solubilization. The previous studies concerned with phosphate solubilization suggest that chelation of calcium ion by organic acids may play a role in solubilization of insoluble phosphate. The present work shows that the presence of organic acids affords increased phosphate solubilization, so additional consideration of the interaction of these organic acids with calcium ion seems warranted.

To understand the interaction of gluconic acid and 2-ketogluconic acids with calcium ion, a theoretical analysis was performed. MINEQL, a model developed at the Massachusetts Institute of Technology (MIT), was used by Frank Sikona of the National Fertilizer and Environmental Research Center to calculate the ability of selected organic acids to chelate calcium and solubilize apatite (a phosphate containing mineral). This model calculated the calciumorganic stability constant over a range of hydrogen ion activities. The calculated values were also used to predict the amount of phosphate solubilization.

At concentrations of gluconic and 2-ketogluconic acids ranging from 1.0 to $0.001 \mathrm{M}$ acid, the model predicted that only a small amount of $0.01 \mathrm{M}$ calcium ion would be associated in 
calcium-organic acid complexes. At high concentrations of organic acids and a calcium concentration of $0.01 \mathrm{M}$, calcium complexation was predicted to increase with decreasing hydrogen ion concentration.

This result suggests that under the biological conditions, some calcium would be complexed by gluconic and 2-ketogluconic acids. Under most conditions the concentration of gluconic acid is about $0.02 \mathrm{M}$ and 2 -ketogluconic is $0.002 \mathrm{M}$. Since the $\mathrm{pH}$ is approximately 3.4 , the model predicts that gluconic and 2-ketogluconic acids will complex less than $20 \%$ of the available calcium. It is uncertain whether this amount of complexed calcium results in the observed phosphate solubilization. The stability of the calcium-organic acid complex and its solubility also determines how significantly the dissociation of RP will be effected.

The model was also used to predict phosphate solubilization for apatite by these organic acids. As hydrogen ion concentration decreased, the model predicted increased soluble phosphate. This result was in direct conflict with experimental data that found that solubilization of RP by mineral acid and organic acid was greater at high hydrogen ion concentration. This result suggested that the hydrogen ion effect on RP was more important for phosphate release than the complexation of calcium. If an insoluble calcium compound is formed between gluconic or 2-ketogluconic acid once hydrogen ion has caused the phosphate release, continual removal of calcium by precipitation of the calciumorganic acid complex could not be discounted.

An experiment was designed to test whether continual calcium removal could be responsible for phosphate solubilization beyond that afforded by hydrogen ion alone. A continuous stirred tank bioreactor was used to grow the bacterium and to provide a constant amount of biomass, hydrogen ion, and organic acid (lixiviant) to a fixed amount of RP contained in a separate container. The amount of lixiviant flowing into the contactor was controlled to maintain a constant amount of active lixiviant in the contactor. In addition to containing $\mathrm{RP}$, the contactors contained either a protonated or sodium loaded cation exchange resin. Controls contained no resin.

Results of this study showed that the presence of either the proton or sodium loaded cation exchange resin loop afforded increased amounts of soluble phosphate (see Figure 2). Although not conclusive, the findings of this study suggested that removal of calcium ion afforded increased solubilization of phosphate, because calcium ion acted to either precipitate free phosphate or alter the activity of the organic acids. This result, combined with results of abiotic experiments with hydrogen ion in the presence of organic acids. suggested that continual removal of calcium ion by organic acid binding was contributing to the observed phosphate solubilization.

\subsubsection{Biochemistry and Genetic Control.}

Biochemical and genetic factors that control the synthesis of gluconis or 2-ketagluconic acids hold interesting potential for enhancing phosphate solubilization. A collaborative effort between the Idaho National Engineering Laboratory (INEL) and Dr. A. Goldstein, California State University at Los Angeles, is striving to characterize genetic parameters and biochemical species that control and participate in the solubilization process.

Based on the assumption that solubilization was caused by acidification and calcium binding with extracellular organic acids, initial activities focused on determining whether phosphate solubilization ability was genetically controlled.

Preliminary efforts to isolate the mineral phosphate solubilizing gene (Mps) were directed at Erwinia herbicola, since prior efforts by Goldstein (see Reference 9) had indicated that this organism contained a gene for solubilization of phosphate and it could be transferred. A plasmid, which was thought to contain Mps, was isolated from $E$. herbicola. Using gene splicing techniques, a fragment of the E. herbicola plasmid was incorporated into a known plasmid from Esherichia coli. When this modified plasmid was 


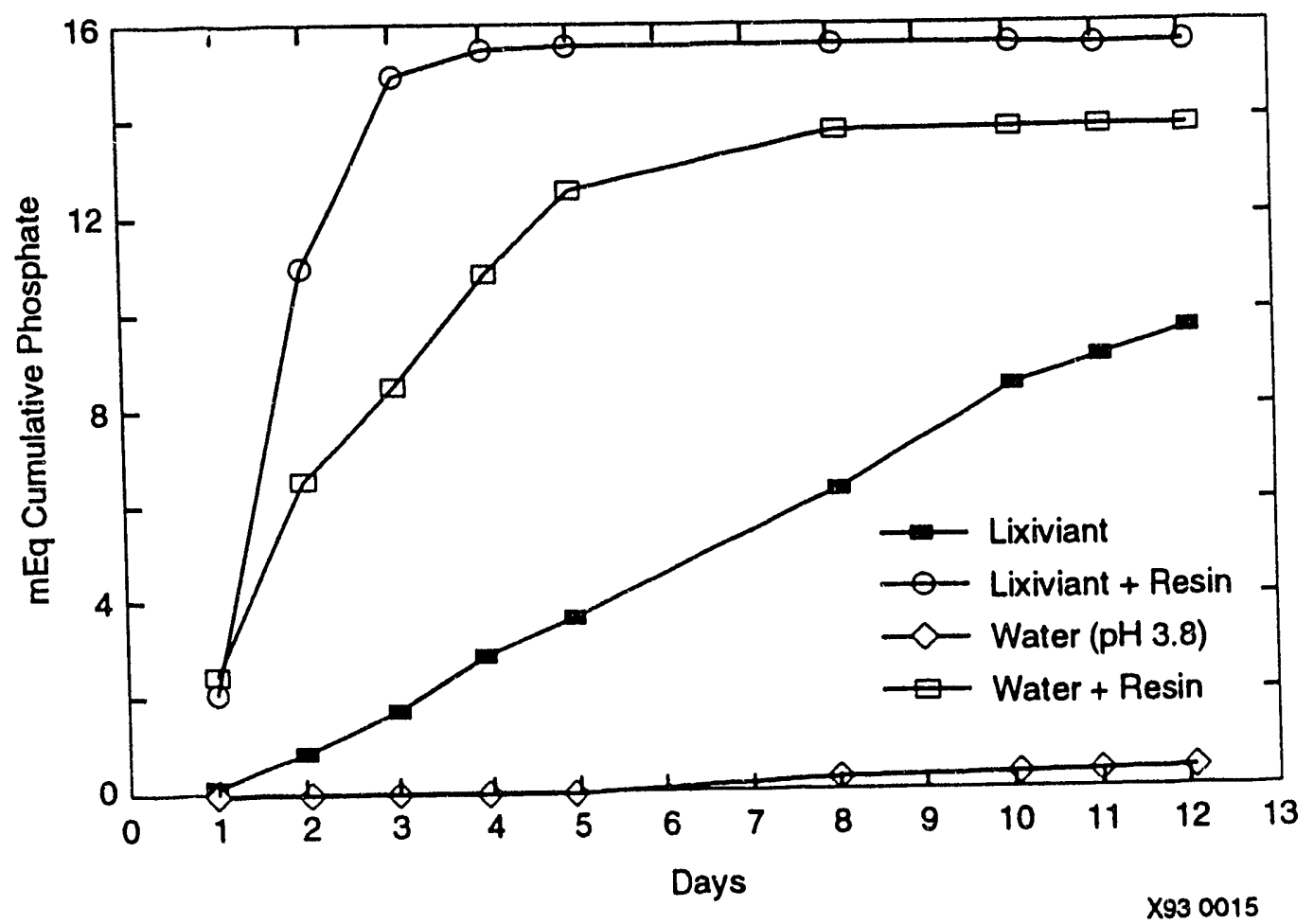

Figure 2. Quantity of phosphate solubilized from RP in contact reactor with and without $\mathrm{H}$-form cation exchange resin. Note: $1 \mathrm{mEq}=32 \mathrm{mg} / \mathrm{L}$.

reincorporated into the bacterium, the recombinant $E$. coli was found to actively solubilize phosphate from insoluble phosphate forms. Further, gene expression induced synthesis of gluconic acid, which was not produced by the original E. coli.

This finding implied that the fragment of $E$. herbicola contained information necessary for gluconic acid production. In bacterial systems, gluconic acid can be synthesized from glucose either by glucose phosphorylation to glucose-6-phosphate or by direct oxidation of glucose to gluconic acid. The direct route to gluconic acid appears to be associated with the bacterial membrane. Conversion of glucose is catalyzed by glucose dehydrogenase $(\mathrm{GdH})$. $\mathrm{GdH}$ belongs to a clüss of quinoproteins having a pyrolo-quinoline quinone (PQQ) as a prosthetic group, which is required to activate the inactive apoenzyme (a-GdH). The components of GdH can be produced separately as a-GdH and PQQ. $\mathrm{PQQ}$ can combine with $\mathrm{a}-\mathrm{GdH}$ at a later time to form the holoenzyme (GdH). An active GdH may also be synthesized.

Expression of gluconic acid production by the recombinant $E$. coli suggested that either a-GdH, $\mathrm{PQQ}$, or $\mathrm{GdH}$ were being produced by the added gerie fragment. In a separate study, E. coli was shown to have a PQQ inducible gluconic acid pathway and constitutive production of a-GdH was suggested. Assuming that the present $E$. coli was similar to the reported strain, the $E$. herbicola gene fragment (Mps) must provide a synthetic route for $\mathrm{PQQ}$.

Amino acid homology exists for a variety of quinoprotein dehydrogenases whose encoding genes have been sequenced. This homology can be used to tentatively identify another GdH gene. A gene having a high degree of homology with genes of two cloned membrane bound GdH systems has been used to prepare a DNA probe. This probe can be used to identify similar nucleotide sequences. 
When this probe was hybridized to DNA from $P$. cepacia, a single band was observed. This indicates that some portion of the genome contained elements of the GdH gene. Thus, an attempt to identify the PQQ synthase gene in $P$. cepacia was made. Following transformation, four recombinant $E$. coli colonies were produced that displayed an ability for solubilizing insoluble phosphate $\left({ }^{+} \mathrm{GdH}\right)$.

In another experiment, the wild type $P$. cepacia was exposed to nitrosoguanidine. Six mutants were isolated that overproduced gluconic acid. One of the mutants was able to generate more than 400 times the amount of acid produced by the wild type organism. GdH vesicles were isolated and purified protein obtained from the wild type and $\mathrm{GdH}^{++}$organisms. Analysis of the extracted material showed ten times the GdH activity for the mutant as compared to the wild type. These results suggest that genetic control for acid generation exists and is related directly to $\mathrm{GdH}$ enzyme activity. As yet, these mutants have not been evaluated for phosphate solubilization to determine if increased gluconic acid production translates into increase phosphate solubilization.

In summary, results of biochemical and genetic studies with phosphate solubilizing organisms show that enhance mineral phosphate solubilization exhibited by $P$. cepacia is linked to extracellular glucose oxidation to gluconic acid by $\mathrm{GdH}$ located on the membrane surface. These data also show that genetic control over the oxidation process can be altered by mutagenesis. Four mutant enhanced acid producing variants of $P$. cepacia have been produced. The use of DNA probe methods further indicates that the gene that codes either for GdH or PQQ is present in P. cepacia, and provides additional evidence to support quinoprotein $\mathrm{GdH}$ oxidation of glucose to gluconic acid.

2.3.6 Effect of Soluble Phosphate. Literature reports suggest that for certain organisms, the concentration of soluble phosphate could inhibit phosphate release. The influence of soluble phosphate on the release of insoluble material has been determined in two unrelated studies. In one study, soluble phosphate was added to the glucose, minimal salts medium before introduction of the bacterium and RP. The amount of soluble phosphate added was more than that anticipated to be produced by the solubilization process. The amount of solubilization for cultures with and without added soluble phosphate showed no indication that soluble phosphate had an effect on RP solubilization. In studies that used the cation exchange resin to remove calcium, higher phosphate solubilization was obtained. Phosphate inhibition was not observed when the daily amount of phosphate release was examined and suggested that continuous removal of soluble phosphate was not necessary for optimal process operation.

Based on these results, it was determined that at the levels of soluble phosphate studied, phosphate did not inhibit RP solubilization. Further, these results indicated that if mechanisms were developed to increase the amount of solubilization and the ultimate soluble phosphate concentration in the lixiviant, phosphate leve $\epsilon_{1,}$ would not limit the attainable concentration of soluble phosphate.

2.3.7 Influence of Kerogen. An cdor characteristic of hydrocarbons is noted in bioprocessed solutions obtained from RP processing. Analysis of RP shows that it contained about 3\% carbon. This carbon is associated with highly oxidized organic material referred to as kerogen or a precursor to kerogen. Since this peculiar odor is not detected when RP is processed with either organic or mineral acids, microbial interaction is implied.

To investigate this interaction, analysis of the organic material present in the virgin and bioprocessed material was performed using pyrolysis gas chromatography coupled with mass spectroscopy (GC/MS). The virgin ore produced a GC/MS spectrum that was not characteristic of usual bituminous rocks, such as tar sands and oil shale. These bituminous rocks were characterized as having organic materials that had experienced water-washing, heating, pressure, and migration effects, which lead to increased bulk organic molecular weight, polymerization, and loss of 
original organic character. The spectrum showed the organic material to be represented by organic compounds derived from partial chemical degradation of fatty acids characteristic of the lipids of organisms present at the time of deposition of the RP. In contrast, the GC/MS spectra obtained for the bioprocessed material showed extensive oxidation of the native organic compounds. Further, relative volatile low molecular weight constituents were measured. The detection of new low molecular weight species and the oxidation of more refractory compounds indicated that the microorganism was degrading (oxidizing) the original organic matrix. The production of these low molecular weight compounds was responsible for the detected hydrocarbon odor. Further, this finding suggested an interesting possibility that the microorganisms could be using the native organic material as a carbon source. The metabolism of the RP organic constituents was considered to be a possible augment to carbon substrate needed for growth of the organism. However, the ability of this material to cause release of phosphate from RP was not determined.

\subsubsection{Postulated Mechanisms for Bacte-} rial Solubilization. There is no definitive mechanism for phosphate solubilization by $P$. cepacia. These studies have provided considerable information and clues as to the mechanism. Solubilization of insoluble phosphate is not a primary process, but is the consequence of processes associated with the transport of carbon substrates across the bacterial membrane. Based on tentative evidence for the GdH enzyme complex, this bacterium appears to use gluconic acid as a way of transforming glucose so that the modified carbon compound can be transported across the bacterial membrane. This supposition is based on the fact that during early culture growth and for growth of the organism under conditions of limited carbon source, very little gluconic acid is free in the culture medium. During periods of maximal carbon utilization and conditions of limited carbon availability, the gluconic acid produced by the GdH enzyme complex is immediately transported across the bacterial membrane. As the cell approaches latent growth conditions, the energy demand of the cell declines and the transport mechanism is inhibited or shut down. Since the GdH enzyme complex resides on the outer membrane, it is probably not controlled and continues to oxidize glucose to gluconic acid. If the gluconate transport process is inhibited or shut down, the glucnnic acid is able to diffuse away from the membrane and appears in the media.

Solubilization studies have shown the importance of high hydrogen ion concentrations. The microorganism produces hydrogen ions, and this production is indicated by the drop in $\mathrm{pH}$ as the culture grows. To understand how hydrogen ions are produced, a mitochondrial model is used to represent the bacterial membrane and the transport processes occurring within this membrane. The chemosmotic hypothesis ${ }^{11}$ postulates that the free energy of electron transport occurring in the mitochondrial membrane of eucaryotic cells is conserved by pumping hydrogen from the cytoplasm to the membrane interspace. A similar mechanism of hydrogen pumping is known to occur in procaryotic cells (bacteria). The potential generated by this gradient in hydrogen is used to transport negative ions, such as gluconate, across the membrane and drive ATP synthesis. The need for active electron transport is a direct consequence of the phosphorylative oxidation of carbon substrates. This process explains the rapid appearance of hydrogen ion in the medium during initial stages of bacterial growth. Under conditions of high metabolic activity, hydrogen ion concentration in the membrane interspace can potentially approach conditions characteristic of strong acids or super acids. Studies have shown that under similar $\mathrm{pH}$ conditions, bacterial medium in contact with RP produces more solubilization than that produced by the same amount of hydrogen ion produced by mineral acid. This high hydrogeit ion concentration in the membrane may be partially responsible for enhanced RP solubilization.

Studies have also shown that the presence of organic acids enhances solubilization. The influence of organic acids may be from dissociation to produce additional hydrogen ion and binding or complexation of calcium. Since most organic acids are weakly dissociated at the $\mathrm{pH}$ of phosphate solubilization, the amount of additional 
hydrogen ion produced would be small. If gluconic acid is transported across the membrane as the anion, then a substantial amount of additional hydrogen ion may be generated during times of intense metabolic activity. Theoretical stability constants for calcium-organic acid suggest that small amounts of calcium may be complexed or bound by the organic acids. Through binding of calcium ion, RP solubilization may be enhanced by shifting the equilibrium to favor free phosphate anion formation. It is clear that calcium ion plays an important role in determining the amount of released phosphate. The ion exchange studies show that when calcium is removed from the media, higher levels of soluble phosphate are attained.

Thus, the solubilization of RP is the result of the high hydrogen ion concentrations in the medium and membrane interspace. This implies that contact of the microorganism with RP is critical to release of phosphate. Organic acids have a role in binding and complexing calcium ion. Ultimately, the stability constant of the calcium-organic acid determines the amount of calcium ion removed from reactions with soiuble or insoluble phosphate. The level of soluble phosphate present in the lixiviant is controlled by the availability of calcium to form calcium phosphate precipitates.

\subsection{Preliminary Process Research}

As data became available to suggest that microorganisms could be used to reproducibly remove phosphate from $\mathrm{RP}$, attention was given to defining a process in which the biological phenomena could be employed. A number of largescale bioprocesses, such as wastewater treatment, alcohol fermentation, and mineral leaching were examined for possible adaptation. The wet acid process for phosphate recovery was also a viable candidate, since there were similarities between the apparent mode of phosphate release for the wet acid process and the bioprocesses. If the bioprocess resembled an existing process, process knowledge would reduce engineering development and encourage increased industry accep- tance. An initial attempt to adapt the existing wet acid process flow sheet (see Figure 3 ) resulted in the flow sheet shown in Figure 4.

Subsequent research has attempted to characterize properties of each of the identified unit operations and to determine additional unit operation needs. To confirm that a continuous process was feasible, several laboratory bench top reactors were constructed. Studies were conducted with these reactors to identify requirements and design information for the growth of microorganisms and production of lixiviant. Various modes of contacting the lixiviant with the RP were investigated. Dicalcium phosphate precipitation was examined as a possible product recovery method. As more information concerning the mechanism of biological phosphate solubilization was gained, the need to add a unit operation to control calcium was found to be necessary. A method to manage calcium ion concentration in the contactor portion of the process was developed. Based on results obtained by these various studies, a set of process design and operation parameters were identified.

2.4.1 Laboratory Bench Top Units. Early bench top units consisted of either a stirred tank or column air lift bioreactor to provide optimal growth conditions for the microorganism. These bioreactors were designed so that a steady state flow of fresh nutrients and effluent of lixiviant could be maintained. The lixiviant produced by the reactor was held in a transfer tank, which was used to supply the RP contact reactor. The stirred tank bioreactor configuration was used for bacterial growth, and the air lift reactor was used to grow the fungus. As previously stated, problems obtaining reproducible growth of the fungus, led to a laboratory reactor configuration that solely supported the growth of the bacterium. This stirred tank bioreactor was of commercial design and provided control of the reactor temperature, $\mathrm{pH}$, and addition of nutrients.

Later unit configurations were modified versions of this basic configuration. One version of this configuration consisted of the stirred tank bioreactor and three contact cells (see Figure 5). 

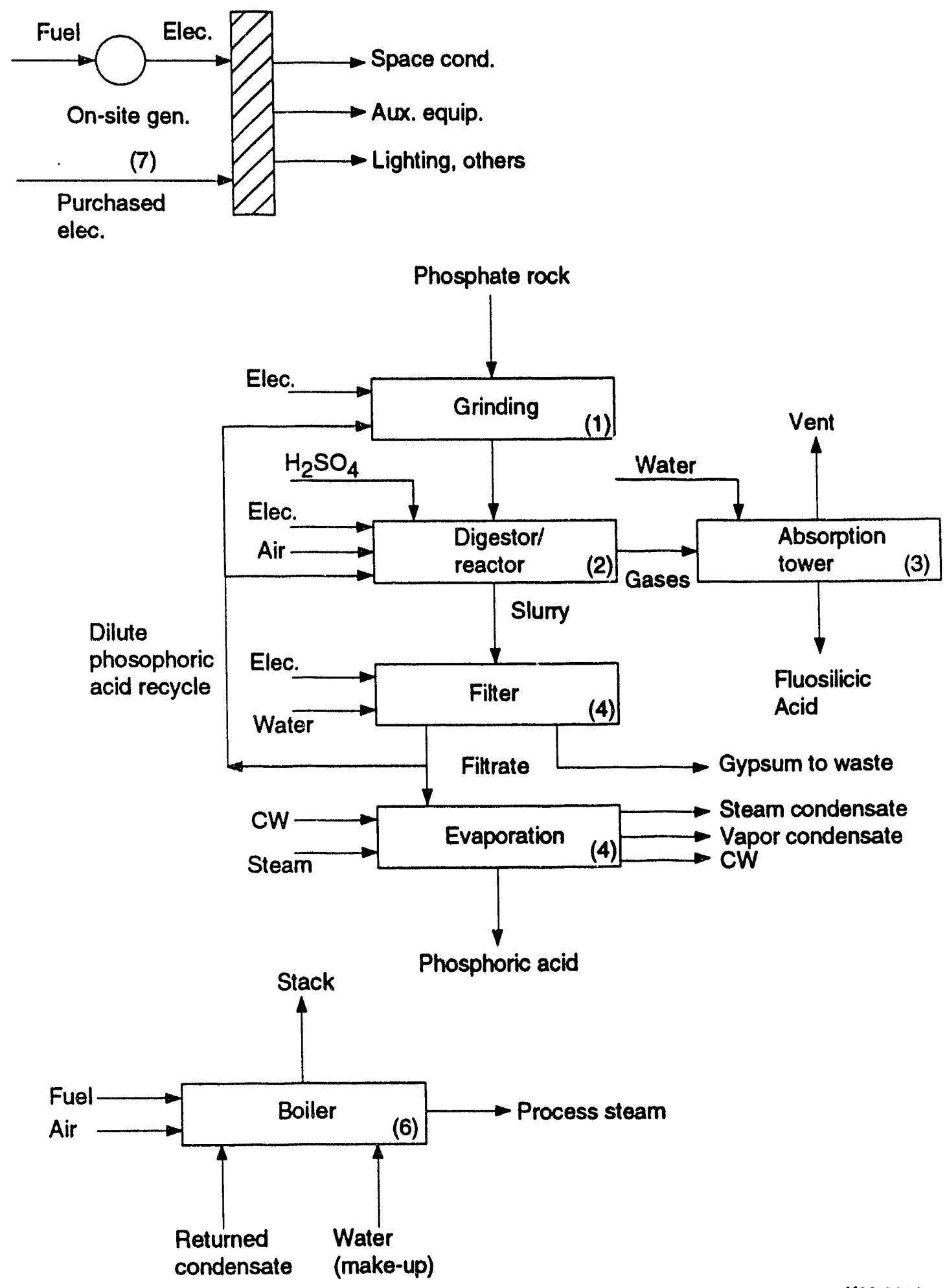

X93 0011

Figure 3. Flow diagram for phosphoric acid wet process. 


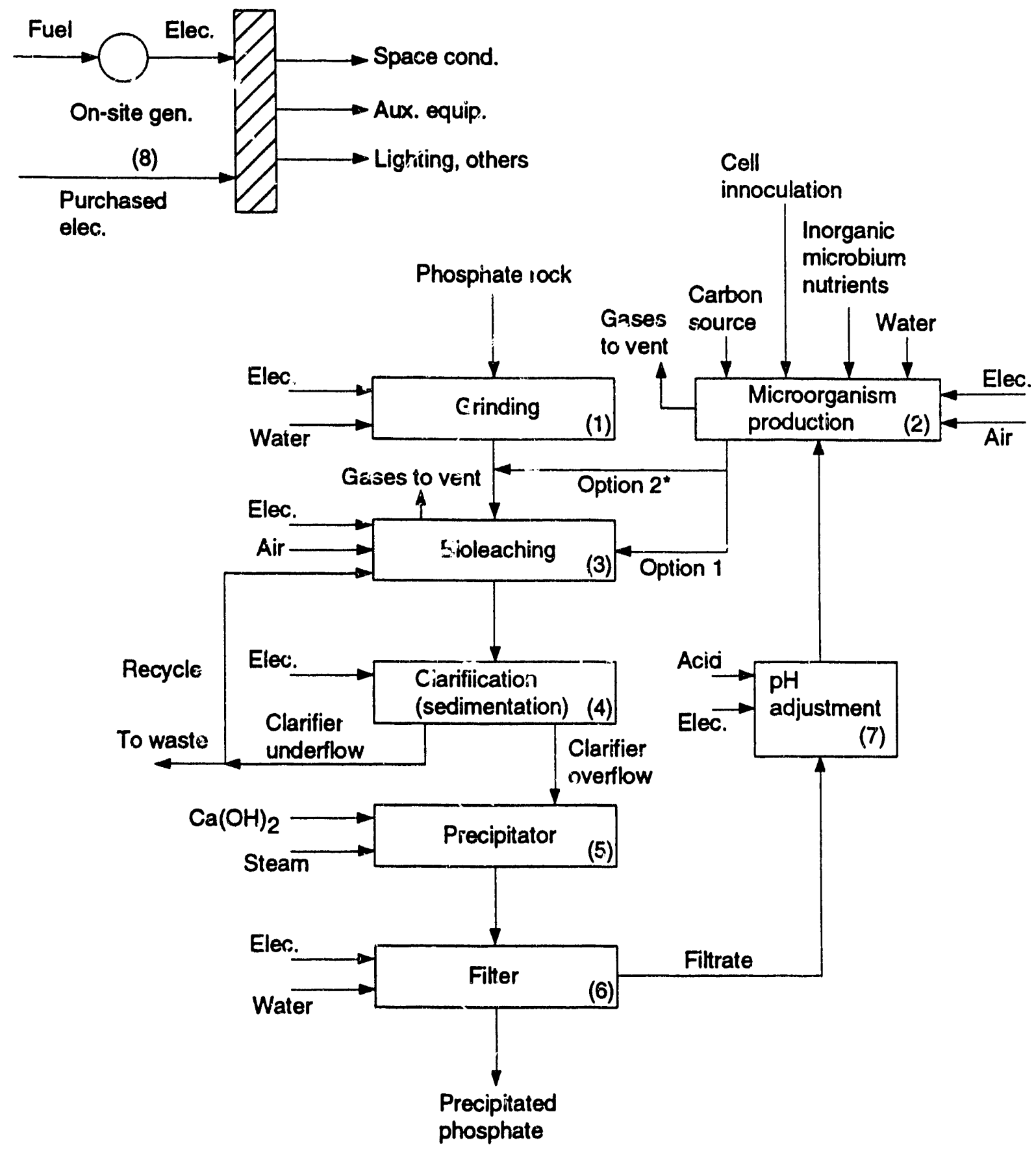

- If a Beneficiation Process is involved

Figure 4. Flow diagram for conceptual biosolubilization process. 


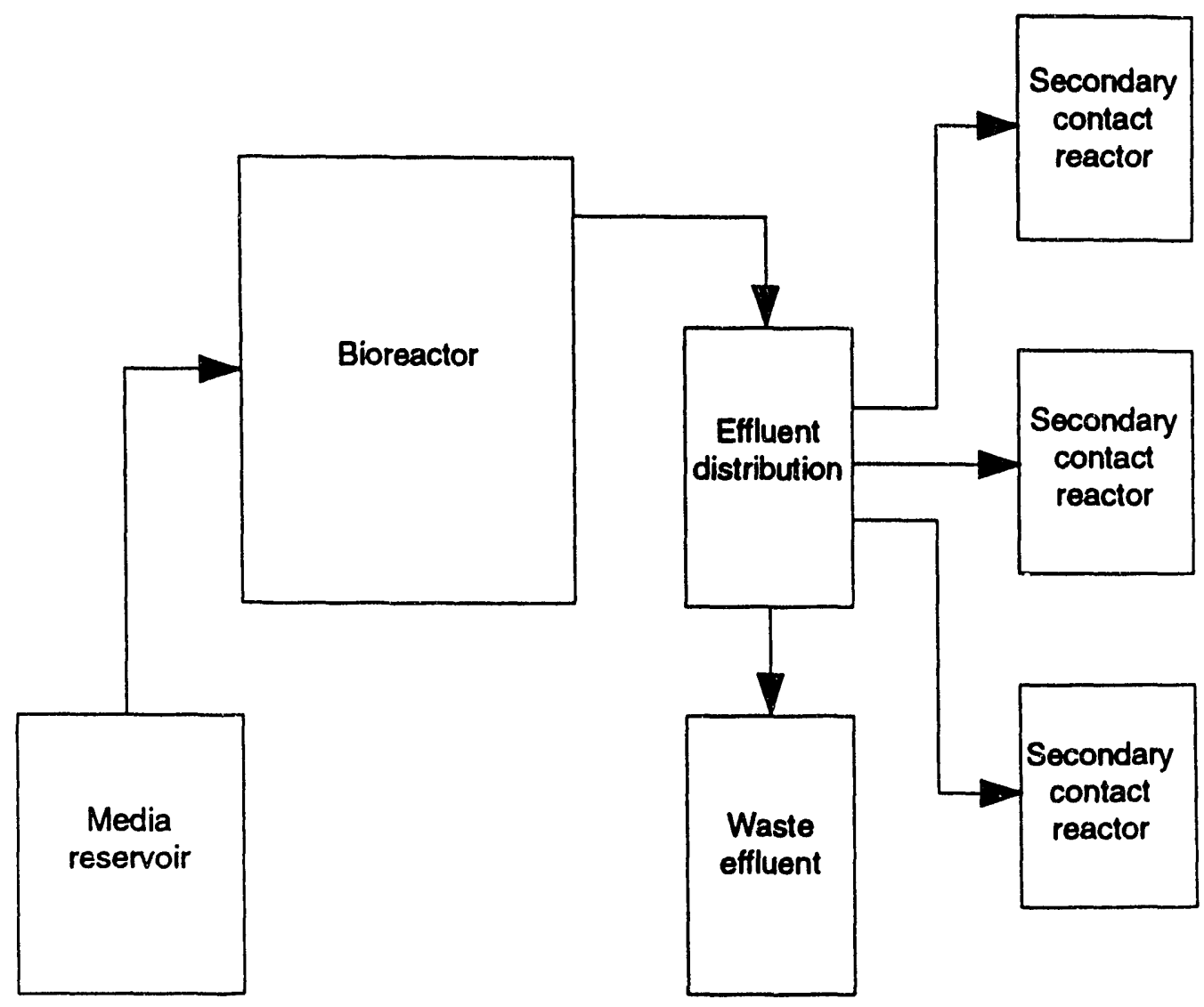

X93 0010

Figure 5. Schematic of process for continuous biosolubilization of RP.

This reactor/contactor configuration was used for most mechanism studies. Studies designed to characterize the nature of the bioreactor (fermentor) replaced the conventional stirred tank commercial reactor with a utility reactor. The utility reactor consisted of a 1-L resin reaction vessel, stirrers, liquid pumps, and heating elements. If the $\mathrm{pH}$ of the reactor was to be changed, $\mathrm{pH}$ was adjusted by adding a predetermined amount of sodium hydroxide. Comparisons were made between fermentor microorganism growth and $\mathrm{pH}$ control.

Various contactor configurations were evaluated over the course of this investigation. These configurations included a stirred tank, purgedsegmented trough, fluidized bed, and percolation column. To evaluate scale-up potential, a 10-L bioreactor was employed to grow up bacterium and a 5-L stirred contactor was used to extract phosphate.

2.4.2 Fermentor Characterization. Commercialization of bioprocess solubilization requires an economical bioreactor for producing biomass, maintaining the microorganism in the proper growth stage for optimal production of phosphate releasing agents, and producing a large, consistent amount of lixiviant (cells plus active agents). Previous studies relied on commercial bioreactors suited for research. A similarly designed industrial reactor would not be economical. To determine the degree of sophistication required to grow and maintain the phosphate solubilizing organism, a simple bioreactor was constructed using 1-L wide-mouth, resin reaction kettles. The jars were covered with a multiported lid. A Teflon gasket was clamped 
between the body and top of the reactor to make a gastight seal. The medium was stirred mechanically. Air was provided by a sparge tube. Liquid input and output was controlled by mechanical pumps. No monitoring instrumentation was employed within the reactor.

Control of $\mathrm{pH}$ and lixiviant feedback for optimal carbon source utilization were evaluated. To determine the need to control the bioreactor $\mathrm{pH}, \mathrm{a}$ comparison study was performed between a utility reactor having no $\mathrm{pH}$ control and one in which a predetermined amount of sodium hydroxide was added to maintain $\mathrm{pH}$. The bacterial cell density and $\mathrm{pH}$ were monitored in the effluents produced by the two reactors. Over a 20-day per id, the $\mathrm{pH}$ of the uncontrolled reactor averaged $3.1 \pm 0.1$ while the reactor having continuous base addition averaged 3.4. Cell numbers for the uncontrolled reactor were an average of three times less than the value in the controlled reactor. This study demonstrated the need to maintain $\mathrm{pH}$ in the bioreactor to obtain optimal growth of the organism. This can be done by adding a predetermined amount of base.

The effect of recycled effluent on growth was also determined. The target ratio of feed of fresh nutrient medium to recycled effluent was $75 \%$ fresh to $25 \%$ recycled. Actual established feed rates were $72 \%$ and $28 \%$ for fresh nutrient medium and recycled effluent, respectively. For 6 days, $320 \mathrm{~mL}$ of fluid were continuously removed from the bioreactor daily. During this study, $\mathrm{pH}$ and the number of cells were monitored. No difference was observed between reactors with and without recycle. Based on this finding, the refeed ratio was increased to $50 \%$. No significant difference in effluent $\mathrm{pH}$ or cell numbers was noted when the values were compared to the utility reactor.

Since recycle of effluent appeared to not influence cell numbers and $\mathrm{pH}$, recycle effect on glucose utilization was examined. During this study the three utility reactors were adjusted as follows: (a) R1 had 100\% fresh nutrient feed and no base addition, (b) $\mathrm{R} 2$ had $50 \%$ recycle and base addition, and (c) R3 had 50\% recycle and no base addition. Glucose level in the effluent was monitored daily.

Figure 6 represents the values obtained from the three utility reactors. The average inlet glucose content is indicated by the straight line. Recycle in R2 was started at Day 30. While there was a high degree of variability in the glucose content of the effluents, values for R1 and R3 remained essentially constant even though $R 1$ had no recycle. $\mathrm{R} 2$ effluent glucose declined after Day 30 and remained low until Day 80 when a reactor upset condition started to occur. Figure 6 suggests that recycle with a reactor $\mathrm{pH}$ of 3.4 result in greater glucose use by the microorganism.

During the recycle study, surplus lixiviant from the bioreactors was transferred to contact cells containing $10 \mathrm{~g}$ of sterilized RP. Effluents from the contact cells were collected and analyzed for $\mathrm{pH}$, phosphate, and glucose. Soluble phosphate was detected in the effluent of R2/C 2 by Day 8 and in the other two effluents by Day 16. The rates of phosphate solubilization were: (a) $\mathrm{Rl} / \mathrm{Cl}$ : $102 \mathrm{mg} / \mathrm{L}$, (b) R2/C2: $166 \mathrm{mg} / \mathrm{L}$, and (c) R3/C3: $134 \mathrm{mg} / \mathrm{L}$. The rate of $\mathrm{R} 2 / \mathrm{C} 2$ was equal to that obtained for other studies where the material was grown in a bioreactor with automatic $\mathrm{pH}$ control.

The capacity of the bioreactor used to grow cells and lixiviant for leaching is sized based on the volume of liquid needed to be supplied to the contactor, metabolic rate of the organism, and doubling time of the organism. Based on trial and error, bioreactor size to contactor volume should be approximately two to one. Further, the bioreactor should be able to supply a lixiviant volume of one contactor exchange-out per day.

2.4.3 Contactor Studies. Separation of the growth of the microorganism and leaching of phosphate was determined to be better when the processes were conducted in separate containers. The contactor concept was new to bioprocessing, since most bioprocesses generally grow the microorganism in the presence of the material to be processed. No knowledge base relating to contactors existed. Investigation of various types of 


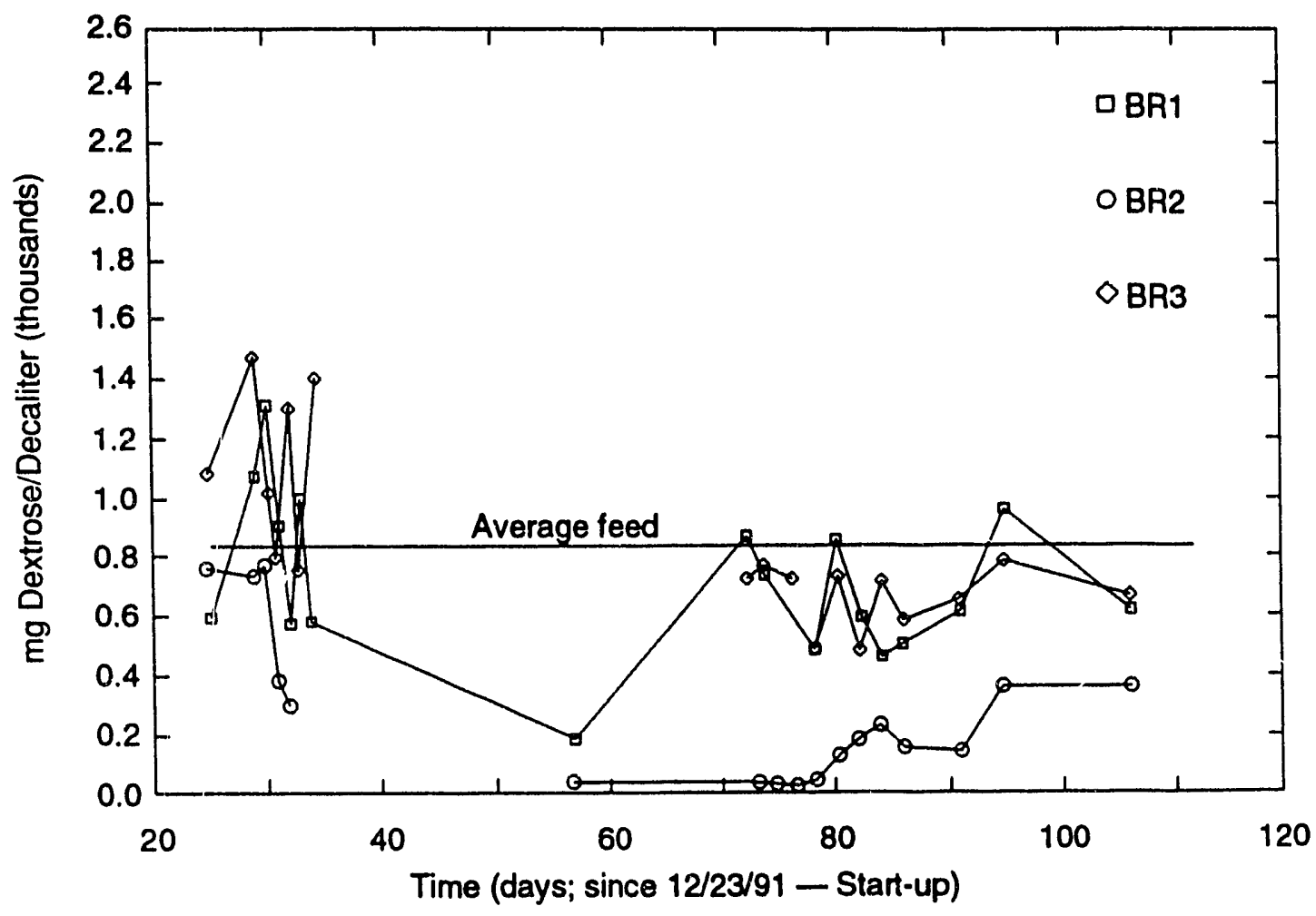

$\times 930014$

Figure 6. Glucose analysis of lixiviant from utility biorearıors over time for recycle versus no recycle.

contactors, such as percolation beds, fluidized beds, stirred tanks, and aerated troughis was necessary to determine the performance characteristics of these contactors.

2.4.3.1 Stirred Tank. The stirred tank contactor was initially studied since it is similar to the wet acid contactor. A laboratory-scale contactor was constructed (see Figure 7). The small volume of this contactor limited the amount of RP used in each study and the lixiviant flow rates to values comparable with the commercial 1 to 2 - $\mathrm{L}$ bioreactor. Agitation of the RP and lixiviant was provided by a magnetic stir bar.

Contactor RP loading factor, influence of lixiviant flow rate, and ability to obtain RP solubilization were evaluated. The first study was performed to evaluate RP loading effects. Three contactors were set up in parallel, and each contactor was loaded with one of the following amounts: $0.1,1.0$, and $10.0 \mathrm{~g}$ of RP. A constant flow of lixiviant was established across each contactor so that $0.125 \mathrm{~L} / \mathrm{d}$ was passed through the contactor.

Data from this study (see Table 5) showed that all the available phosphate was removed from the $0.1 \mathrm{~g}$ loaded contactor within $72 \mathrm{~h}$. Forty-four percent of the available phosphate was removed from the $1.0 \mathrm{~g}$ loaded reactor, and solubilization appeared to still be occurring at $72 \mathrm{~h}$. Initiation of phosphate solubilization in the $10 \mathrm{~g}$ loaded contactor was not observed until about $90 \mathrm{~h}$. Solubilization increased from this point in a stepwise fashion with a large increase observed between 220 and $290 \mathrm{~h}$. At the highest solubilization rate, only $3 \%$ of the $10.0 \mathrm{~g}$ of RP was solubilized.

This initial study proved that continuous RP solubilization could be performed. This and other similar studies indicated that there was an apparent load factor for a fixed flow of lixiviant across the contactor. This load factor was expressed as a 


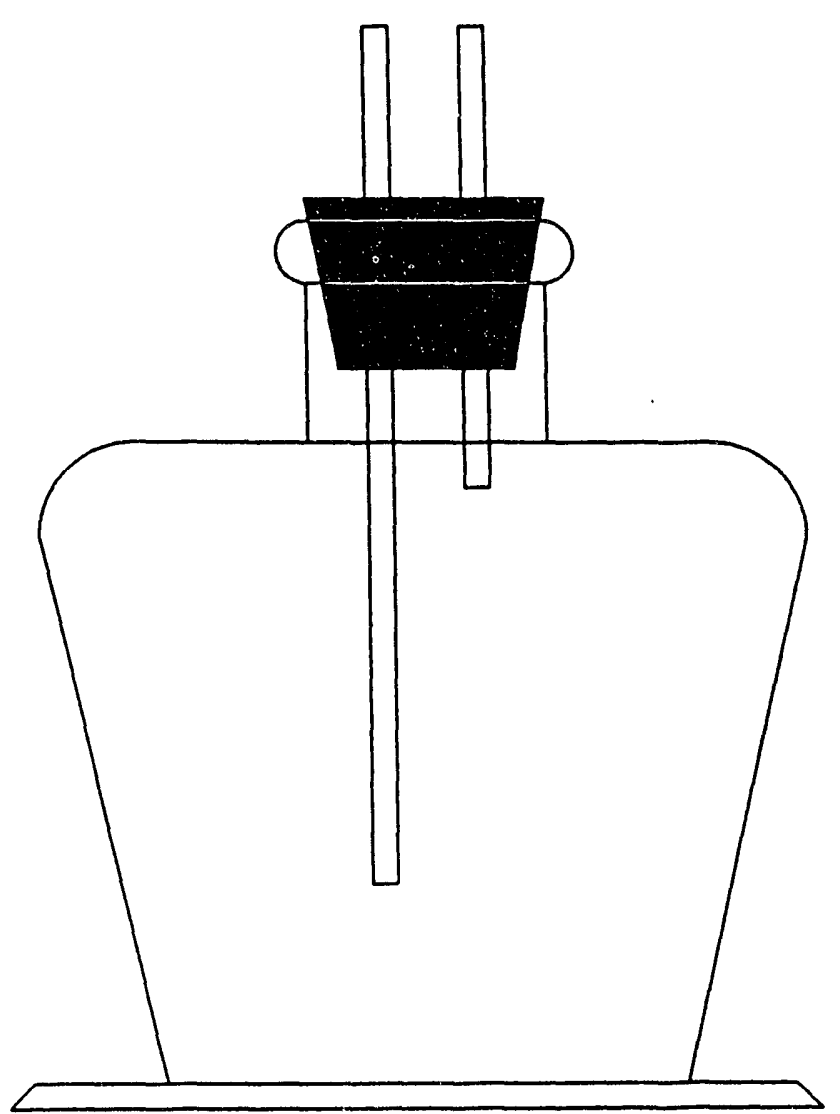

X930009

Figure 7. Example of $125 \mathrm{~mL}$ biocontact reactor. lag time for solubilization to occur and as fixed amount of soluble phosphate producing agent per unit of lixiviant added.

These initial studies suggested that the throughput of lixiviant was important to the total amount of phosphate solubilized per unit of time. An additional study was performed where the lixiviant flow was varied between 200 and $400 \mathrm{~mL} / \mathrm{d}$ in steps of $100 \mathrm{~mL}$ through three contactors each containing $1.0 \mathrm{~g} \mathrm{RP}$. The amount of cumulative phosphate solubilized by each flow rate was found to increase as flow rate increased from 200 to $300 \mathrm{~mL} / \mathrm{d}$. Further, lag time for onset of solubilization was reduced. At the highest flow rate $(400 \mathrm{~mL} / \mathrm{d})$ there was significant wash out of RP. These findings suggested that for a given contactor volume there is an optimum flow rate of lixiviant for obtaining optimal phosphate solubilization. This optimum flow rate is determined by the amount of biomass, concentration of leach agent in the lixiviant, and amount of RP being processed. When the flow rate exceeds three times the volume of the contactor, turbulence is sufficient to wash RP out of the contactor.

The results of these studies suggested that less than $1 \%$ solids is optimal for operation of the stirred tank. The optimal flow through the reactor was approximately three times the contactor

Table 5. Continuous leaching of phosphate from various amounts of RP as a function of lixiviant flow rate.

\begin{tabular}{cccccc}
\hline g of RP & mg PO4 & Time in days & pH & Flow L/d & $\mathrm{Q}^{\mathrm{a}}$ \\
\hline 0.1 & 18 & 3 & 3.1 & 0.125 & 0.480 \\
1.0 & 58 & 11 & 3.4 & 0.125 & 0.042 \\
10 & 42 & 11 & 3.4 & 0.125 & 0.003 \\
1.0 & 190 & 10 & - & 0.200 & 0.095 \\
10 & 150 & 10 & - & 0.200 & 0.008 \\
1.0 & 210 & 10 & - & 0.400 & 0.053 \\
10 & 330 & 10 & - & 0.400 & 0.008
\end{tabular}

a. $Q=$ fraction material solubilized/liquid volume. 
volume per day to limit the amount of solids washed out. Since this flow rate may not be an optimal value for maximal phosphate extraction, a method to recover washed-out RP was evaluated.

The reactor was modified to minimize the amount of RP washed out by the $400 \mathrm{~mL} / \mathrm{d}$ flow. The $125-\mathrm{mL}$ contactor was loaded with $1 \mathrm{~g}$ of RP and lixiviant flow rate set at either 200 or $400 \mathrm{~mL} / \mathrm{d}$. The solubilization rate was found to correlate directly with flow rate. This result confirmed the incortance of lixiviant flow rate in relation to the contactor loading density.

2.4.3.2 Aerated Trough. Studies associated with an unrelated project had shown that an aerated trough was useful for processing solids, since this trough could replicate a sequence of plugged flow, stirred reactors. A V-shaped trough reactor $50 \mathrm{~cm}$ in length by $13 \mathrm{~cm}$ in depth by $10 \mathrm{~cm}$ in width was constructed. The working volume of this contactor was between 1 and $1.5 \mathrm{~L}$. The interior of the trough was divided into eight sections separated by equally spaced baffles. Mixing in the contactor was provided by a perforated tube running the length of the bottom of the trough. The residence time of the liquid was controlled by the lixiviant exit flow rate. RP was added to the initial section of the trough after the trough was filled, and it was subsequently moved to other sections further along the trough by the lixiviant flow.

Two initial studies were conducted to evaluate the trough contactor. These consisted of monitoring the solubilization at $1 \%$ slurry density and flow rates of either 400 or $800 \mathrm{~mL} / \mathrm{d}$. The average rate of solubilization of phosphate was found to be $400 \mathrm{mg} / \mathrm{L}$ and $200 \mathrm{mg} / \mathrm{L}$ of lixiviant, respectively, as compared to the $125 \mathrm{~mL}$ stirred tank reactor value of $122 \mathrm{mg} / \mathrm{L}$. For a slurry density of $1 \%$, the flow rate through the trough appeared to have an inverse effect on the rate of solubilization.

Operating the trough at higher solids loading $(5 \%)$ produced an average solubilization rate of $105 \mathrm{mg} / \mathrm{L}$, which was less than that of the
$1 \%$ solids loading. A stirred tank reactor was run concurrently as a control ( $1 \%$ solids) and had a solubilization rate of approximately $176 \mathrm{mg} / \mathrm{L}$.

An interesting observation was noted for the $5 \%$ and $10 \%$ slurry densities. Measurement of the trough effluent $\mathrm{pH}$ noted that the $\mathrm{pH}$ was initially low (pH 3.4). However, $\mathrm{pH}$ steadily increased until by Day 8 it had attained a value of $\mathrm{pH}$ 6.9. A gradient in $\mathrm{pH}$ was also measured between various sections of the trough. The initial section $\mathrm{pH}$ was 3.4 and progressively increased to 7.9 at the exit. The amount of soluble phosphate followed an inverse trend, being high at low $\mathrm{pH}$ and low at high $\mathrm{pH}$.

A study was performed to determine why elevated $\mathrm{pH}$ values were produced in the trough. If a flow rate of $1 \mathrm{~L} / \mathrm{d}$ was maintained through the contactor, the $\mathrm{pH}$ remained low. However, if the flow was reduced to $400 \mathrm{~mL} / \mathrm{d}$, the elevated $\mathrm{pH}$ values were again measured. If the air used for agitation was changed to nitrogen, low $\mathrm{pH}$ values were maintained at the lower flow rates. This finding suggested that the microorganism was exhausting the glucose available in the liquid and was resorting to gluconic acid for a metabolic carbon source. Introduction of nitrogen reduced the availability of oxygen for respiration and also stopped the use of gluconic acid.

Because of problems with accumulation of RP in the later sections of the trough, and a high degree of wash-out, modifications were made to the trough design to smooth out the RP distribution, and a settler was placed in the outlet to recover RP. Solubilization of RP based on these modifications showed that $160 \mathrm{mg} / \mathrm{d}$ solubilization rates could be obtained at $1 \mathrm{~L} / \mathrm{d}$ flow rate for the initial few days. However, after a few days the rate of solubilization declined. Attempts to recycle RP collected in the settler were not very successful. Since considerable redesign of the trough was considered necessary to further evaluate this type of contactor, additional efforts were delayed until other designs had been evaluated.

The most important findings obtained from the trough studies were: a method of solids collection and recycle was necessary to operate at high 
contactor flow rates, and sparge of the trough using air at low lixiviant flow rates caused the $\mathrm{pH}$ to increase. This increased $\mathrm{pH}$ was probably caused by the microbe metabolizing gluconic acid for energy.

2.4.3.3 Fluidized Bed. A fluidized bed bioreactor was designed to maintain a constant dispersal of RP through a given volume of liquid. Fluidization of the solid was accomplished by pumping lixiviant at a velocity through a hole in the bottom of the column sufficient to suspend the RP. Reactor dimensions were $3 \mathrm{~cm}$ in diameter and $518 \mathrm{~cm}$ in height, for a total volume of $14 \mathrm{~L}$. A quantity of approximately $100 \mathrm{~g}$ of 200 -mesh RP could be fluidized by this contactor geometry. Because of the high lixiviant volumes required to make this contactor operate, the bacterium was grown in a $20-\mathrm{L}$ carboy. The contents of this carboy were pumped into the bottom of the column. A makeup stream composed of outflow from the column was provided to give sufficient flow and volume of lixiviant to facilitate fluidization.

The fluidized bed was evaluated during two run periods, 18 and 29 days. The operational parameter for the 18-day run was $100 \mathrm{~g} \mathrm{RP}$ processed by $1 \mathrm{~L} / \mathrm{d}$ of lixiviant throughput. The 29-day run was operated with $150 \mathrm{~g}$ of RP using $6 \mathrm{~L} / \mathrm{d}$ of lixiviant flow. The total solubilized phosphate was determined to be $5.37 \mathrm{~g}$ and $7.74 \mathrm{~g}$ for 18 and 29-day runs, respectively. These values related to 297 and $267 \mathrm{mg} / \mathrm{d}$ solubilization rates. When these rates were normalized by the amount of material processed, 2.98 and $1.79 \mathrm{mg} / \mathrm{g}-\mathrm{d}$ values were obtained. Compared to those obtained for the trough $(16 \mathrm{mg} / \mathrm{g}-\mathrm{d})$ and the stirred tank reactor $(48 \mathrm{mg} / \mathrm{g}-\mathrm{d})$, the amount of phosphate being solubilized by the fluidized bed contactor was not sufficient to warrant further consideration.

2.4.3.4 Percolation Bed Contactor. Percolation bed contactors had been successfully used to leach low grade mineral ores. This suggested that a long-term processing of a large volume of material could be accomplished. To adapt this type of contactor to the RP solubi- lization process, the microbially produced lixiviant was generated in a bioreactor and then pumped on top of a pile of RP. The lixiviant was allowed to percolate down through the RP, and a phosphate rich solution collected at the bottom of the pile. To facilitate flow through the column of $\mathrm{RP}$, sand was added to enhance the porosity of the column, and a negative pressure was placed on the bottom of the column to draw liquid down through the pile of RP.

Two studies of the percolation bed contactor were performed. These studies used 200-mesh RP dispersed in sand. One sample of material was sterilized, and the other sample unsterilized. A total of $1.4 \mathrm{~kg}$ of RP was placed in the bed with approximately $3 \mathrm{~L} / \mathrm{d}$ of lixiviant allowed to flow through the bed. During the first 13 days of operation, greater than 4.48 and $3.84 \mathrm{~g}$ of total soluble phosphate was produced for the sterilized and unsterilized samples, respectively. This represented 640 and $412 \mathrm{mg} / \mathrm{d}(214$ and $137 \mathrm{mg} / \mathrm{L}$ ) rate of solubilization during the most active periud of soluble phosphate production. When normalized by the mass of RP, values of 0.45 and $0.29 \mathrm{mg} / \mathrm{g}-\mathrm{d}$ were realized. After Day 13, additional solubilization did not occur in either bed because of the formation of a dense bacterial mat on the top of the bed. This restricted percolation of material through the bed. The percolation bed was viable for heap processing of material; however, some solution for bed plugging was needed to achieve long-term operation.

2.4.3.5 Modified Stirred Tank. Based on results obtained during the trough reactor studies, which indicated an inert atmosphere in the contactor aided solubilization, a scaled-up stirred tank was investigated using an inert atmosphere above the lixiviant. The contactor had a working volume of $1.5 \mathrm{~L}$ in which a $5 \%$ slurry density was maintained. A $2 \mathrm{~L} / \mathrm{d}$ flow was established through the contactor. After Day 4, solubilization occurred at a rate of $672 \mathrm{mg} / \mathrm{d}$. By Day 17, a total of $8.1 \mathrm{~g}$ had been obtained. An overall rate of $630 \mathrm{mg} / \mathrm{d}$ was achieved. Normalization of this rate for mass of RP processed, yielded $8.38 \mathrm{mg} / \mathrm{g}$-d. By Day 17, a significant portion of 
the RP had been washed from the contactor, and the experiment was terminated.

An additional experiment was performed using a clarifier to permit separation and collection of the washed-out material. The clarifier had a volume of $2.5 \mathrm{~L}$ and a conical raked bottom. The operation conditions for this experiment were $5 \%$ slurry density, $10 \mathrm{~L} / \mathrm{d}$ lixiviant flow, and the contactor purged with nitrogen. Over a 21-day period, approximately $22.4 \mathrm{~g}$ of phosphate was solubilized. The average rate of $1.06 \mathrm{~g} / \mathrm{d}$ was obtained. During a 10-day period, $1.73 \mathrm{~g} / \mathrm{d}$ maximal solubilization rate occurred. Normalization for the amount of RP in the reactor yielded $3.46 \mathrm{mg} / \mathrm{g}-\mathrm{d}$. The theoretical upper limit based on batch studies was $1.92 \mathrm{~g} / \mathrm{d}$ or $3.84 \mathrm{mg} / \mathrm{g}$-d.

Based on various contactor studies, the trough and stirred tank contactors provided the greatest amount of phosphate release per gram of RP. However, since the trough contactor had problems with solids return, the stirred tank was considered to be the best type of contactor for future scale-up activities.

\subsubsection{Critical Solids Loading Density.}

In a continuous process, the solids density needs to be fixed to a value that results in the complete extraction of available phosphate in a single pass through the contactor. This density is the critical solids density (CD) for the process. A solids density above this value will result in the lixiviant exceeding $192 \mathrm{mg} / \mathrm{L}$ soluble phosphate and phosphate being lost as calcium precipitates to the solids waste stream. A solids density below this value will cause incomplete use of the lixiviant. The determination of the $\mathrm{CD}$ for various phosphate ores is critical for process design.

A series of triplicate batch experiments were performed to evaluate $C D$ for various types of phosphate ore. Curves were generated by plotting the maximum concentration of soluble phosphate versus solids density.

In its simplest form, the equation for determining $C D$ is:
$C D=q / x$

where $\mathrm{CD}$ is the critical solids density, $\mathrm{q}$ is the $\mathrm{mg}$ of phosphate solubilized by a liter of lixiviant, and $x$ is the mass fraction of phosphate in the ore. $C D$ values based on $192 \mathrm{mg} / \mathrm{L}$ limiting phosphate concentration for the selected ore evaluated in this study are $1.3,0.91,1.1$, and $1.5 \mathrm{~g} / \mathrm{L}$. These $C D$ values suggest that a solids density of approximately $0.1 \%$ is optimal for the bioprocess, and this value is further substantiated by examination of prior research results.

2.4.4 Calcium Management. The steady state concentration of phosphate in the lixiviant has been in the region of 180 to $200 \mathrm{mg} / \mathrm{L}$ for this study. The mechanism of phosphate solubilization by bacterium and identification of the role of calcium suggests that increasing the concentration of phosphate in the spent lixiviant requires a method of removing calcium from the contactor liquid. The initial success of cation exchange resin for calcium ion removal warrants additional investigation. Other possible methods of calcium collection include solvent/solvent extraction, membrane separation, and selective precipitation. These methods have not been evaluated.

As described above, several cation exchange resins were evaluated for their ability to increase the rate of phosphate solubilization. The presence of the resin increased the rate of phosphate solubilization when the resin was mixed with RP in shake flasks. Small shake flask experiments produced approximately $200 \mathrm{mg} / \mathrm{L}$ of soluble phosphate. Similar experiments with resin added produced about $2,000 \mathrm{mg} / \mathrm{L}$ (a 10 -fold increase) of soluble phosphate. Two possible methods for using ion exchange resins were examiner $:$. These were direct mixing of the resin with $\mathbf{F P}$ in the contactor and an external resin bed through which a portion of the contactor liquid was circulated. Difficulties associated with maintaining contactor agitation favored direct addition of the resin to the contactor. Addition of resin to the 5-L contactor was implemented after 35 days of operation with a fixed amount of RP. The initial 35 days provided a baseline for subsequent experiments. Some increased solubilization was 
obtained, but because of the rapid decrease in solubilization caused by depletion of the RP, determination of the enhancement produced by the resin was difficult. Because of continued mixing problems and a concern that separation of the resin from the spent RP would be difficult, direct addition of resin was abandoned for a recirculating, in-line resin cartridge system. Final design for this system had a sand trap for removing RP fines. The trap was in-line with an ion exchange resin bed.

The amount of soluble phosphate enhancement produced by the in-line cartridge is being evaluated. Initial results suggest that a two to four fold increase in soluble phosphate is obtained. Higher recovery of soluble phosphate may yet be determined. These results suggest that calcium removal is necessary in the final process, and calcium precipitates are responsible for the soluble phosphate concentration not exceeding $192 \mathrm{mg} / \mathrm{L}$.

2.4.5 Product Recovery. Little attention has been paid to product recovery. One method is to treat spent lixiviant with lime $\left(\mathrm{Ca}(\mathrm{OH})_{2}\right)$ to precipitate dicalcium phosphate. Test tube experiments have shown that soluble phosphate levels typical of the spent lixiviant $(200 \mathrm{mg} / \mathrm{L})$ can be precipitated when the solution $\mathrm{pH}$ is increased beyond $\mathrm{pH} 9$ by lime addition.

Based on these test results, an attempt was made to continuously treat the contactor effluent to recover soluble phosphate. Problems removing RP fines from the spent lixiviant precluded continuous operation. Alternately, the amount of lime required for product separation was determined. Approximately $14 \mathrm{~L}$ of spent lixiviant was collected, and residual RP solids removed by centrifugation. Twelve grams of lime was required to obtain $46 \mathrm{~g}$ of wet dicalcium phosphate (1 to 1 ).

Additional work on product recovery is needed. The objectives of this future work will be to develop a method of RP solids removal and to determine appropriate methods for continuous lime addition and product removal.
2.4.6 Summary of Process Data. Results of numerous process-related studies have provided valuable information concerning process design and process operational parameters. Process design information includes:

- A separate bioreactor will be required to produce bacterial growth and lixiviant. A relatively unsophisticated bioreactor can accomplish this requirement. It can be either mechanically or hydrodynamically agitated. $\mathrm{pH}$ control is important for high cell densities, carbon utilization, and organic acid production. pH control can be accomplished by the simple addition of predetermined amounts of base. Recycle of spent lixiviant offers optimal carbon source use.

- The preferred contactor design for the process is a stirred tank contactor. This is simple, shows the highest yield, and is compatible with the existing wet acid process. Air/oxygen exclusion is necessary for pH stability and high phosphate release.

- Phosphate solubilization is afforded by high flow rates of lixiviant. These flow rates require a solids settler, cyclone clarifier, or another solids trap to capture washed-out materials.

- Some form of calcium ion management is necessary to enhance the yield of soluble phosphate. One scheme is to use a cation exchange resin to capture calcium.

- $\quad$ Recovery of the product as calcium phosphate can be achieved by the addition of lime or $\mathrm{CaO}$.

Process related operational parameters in terms of the current state of the art for the bacterial process include:

- Optimal glucose concentration appears to be in the range of $1 \%$ glucose by weight. A low cost nutrient containing glucose can be used in the industrial process. 
- $\quad$ Critical solids density (CD) for the present process is $0.1 \%$ or $1 \mathrm{~g} / \mathrm{L}$.

- Soluble phosphate concentration without calcium management is about $180 \mathrm{mg} / \mathrm{L}$. Incorporation of calcium management may potentially raise soluble phosphate to about $2,000 \mathrm{mg} / \mathrm{L}$.
- One $\mathrm{g} / \mathrm{L}$ of lime addition is required for product recovery when soluble phosphate is $200 \mathrm{mg} / \mathrm{L}$.

Using these design and operational parameters, it is possible to begin to develop a conceptual design for a commercial bioprocess for phosphate recovery. This conceptual design is discussed in the next section. 


\section{PROCESS ENGINEERING ANALYSIS}

\subsection{Introduction}

The objective of this process engineering analysis is to evaluate economic viability and to identify research and development efforts that must be addressed to further develop the bioprocess. As a baseline, the analysis is performed on a production plant sized at $2,000,000$ ton/y of ore processing capability. This plant size is comparable to a typical wet acid plant capacity. Many assumptions are required to complete the analysis at this state of technology development, and the results are considered to be a rough order of magnitude. Further, almost no engineering data exist for bioprocesses. Design and engineering data for wastewater treatment and fermentation technologies are used where possible to provide better estimates.

Processing insoluble phosphate ore (RP) into usable species of phosphorus compounds is highly energy intensive. ${ }^{12-14}$ In past work on this program, energy estimates have been made on the basis of energy consumed per mass of ore processed into phosphorus or soluble phosphate species. The species of soluble phosphate was not considered of major importance, and dicalcium phosphate was selected as the product. Dicalcium phosphate either provided an intermediate product that could be converted to a higher value product, such as food grade phosphoric acid, or could be sold as a product.

The emphasis of this analysis is on evaluating the energy and costs associated with production of a known mass of a given product species, i.e., dicalcium phosphate dihydrate $\left(\mathrm{CaHPO}_{4} \cdot 2 \mathrm{H}_{2} \mathrm{O}\right)$. The shift in emphasis is because different phosphate species have different thermodynamic energy levels. Additionally, size and complexity of the equipment that must be used to process the ore all the way to a salable product must be considered in the manufacturing plant capital costs and must be recovered over the life of the manufacturing plant. The product yield of soluble phosphate per quantity of ore may be different for each process, and must be resolved in the overali economic picture.

To illustrate the thermodynamic energy level effect, the reader is referred to the chemical reactions shown below. In this reaction sequence, oxygen is added to elemental phosphorus, which spontaneously oxidizes to form phosphorus pentoxide, generating $50.5 \mathrm{~J} / \mathrm{g}$ of phosphorus reacted. Water is then added to the phosphorus pentoxide, which spontaneously reacts to phosphoric acid, generating $6.49 \mathrm{~J} / \mathrm{g}$ of additional heat. Hydrated lime is then added to the phosphoric acid, which spontaneously reacts to form dicalcium phosphate dihydrate, generating another $11.7 \mathrm{~J} / \mathrm{g}$ of the initial phosphorus. In total, $68.65 \mathrm{~J} / \mathrm{g}$ of heat are liberated in this reaction. This quantity of heat also represents the minimum thermodynamic amount of heat that would be required to reverse the reaction. ${ }^{15}$ In practice, if a viable process can be demonstrated, it always requires more than the minimum thermodynamic energy to accomplish the reverse reaction.

$$
\begin{aligned}
4 P_{(s)}+ & 50_{2(g)} \rightarrow 2 P_{2} O_{5}(g) \mathrm{DH} \\
= & -50.5 \mathrm{~J} / g \\
2 \mathrm{P}_{2} \mathrm{O}_{5}(g) & +6 \mathrm{H}_{2} \mathrm{O}_{(1)} \\
\rightarrow & 4 \mathrm{H}_{3} \mathrm{PO}_{4(1)} \mathrm{DH} \\
= & -6.49 \mathrm{~J} / \mathrm{g} \\
4 \mathrm{H}_{3} \mathrm{PO}_{4(1)} & +4 \mathrm{Ca}(\mathrm{OH})_{2(s)} \\
& \rightarrow 4 \mathrm{CaHPO} 2 \\
\mathrm{H}_{2} \mathrm{O}_{(c)} \mathrm{DH} & =-11.7 \mathrm{~J} / \mathrm{g}
\end{aligned}
$$

As can be seen, dicalcium phosphate dihydrate is a much lower energy state species that phosphoric acid or elemental phosphorus. If it is possible to manufacture dicalcium phosphate dihydrate that requires large quantities of energy to produce, then it is thermodynamically possible to produce the product at a lower energy cost.

It should also be noted that this process evaluation covers only one scenario for which biosolubilization has been suggested. Other processes 
have been postulated, and may have promise for commercial use. Processing of low grade ore, ore preprocessing, tailings postprocessing, and in situ processing have all been suggested as candidate uses of the bioprocessing method. Additionally, other benefits such as environmentally friendly waste streams and byproducts that can be used as nutritional supplements may be realized via use of the bioprocess.

\subsection{Process Flow Diagram for Bioprocess}

Figure 8 is a process flow diagram that illustrates the flow logic of the conceptualized bioprocess. The flow diagram contains each of the major unit operations that are considered necessary to support the manufacture of dicalcium phosphate dihydrate.

The first step in the process is to reduce the particle size of the ore. A ball mill (similar in nature to that of the wet acid process) has been selected for this application. In the wet acid process, the ball mill generally reduces the ore size such that $60 \%$ is -200 mesh or finer. ${ }^{16}$ Most of the data on the biosolubilization process have been generated using RP of the 200-mesh particle size. There is preliminary evidence from in-house research that suggests that solubilization via the bioprocess occurs at the same rate when 20-mesh ore is used. However, it is assumed that 200-mesh ore will be used and a continuous ball mill for wet grinding will be needed.

As the ore is being processed, a bioreactor is culturing microorganism lixiviant to be used in the leaching step. The lixiviant content is determined by the type of carbon nutrient, nutrient concentration, biomass, and flow rate of liquid through the bioreactor. The bioreactor is essentially a large tank reactor in which agitation is achieved by sparging air through the vessel in such a way as to cause gentle but complete mixing. The air also provid 3 the oxygen that is consumed in the metabolic ractions. Nutrients and the metabolic energy for the microorganisms are supplied by glucose and other trace minerals, such as potassium, cobalt, copper, and iron nitrates. The flow of sterile materials into the bioreactor includes recycled lixiviant, glucose, makeup water, and trace minerals. The bioreactor will maintain a steady state population of microorganisms and have a mean cell residence time of 1 day.

The ore and lixiviant are then mixed in a contactor. The contactor operates in an anaerobic condition with nitrogen purge. The ideal contactor configuration has not been completely investigated, but it is assumed that a continuous 3-5 stage contacting system will be required to achieve maximum extraction efficiency. For this evaluation a three-stage contactor is used. Solidsliquid separation is required between each contactor to achieve countercurrent flow of lixiviant and RP. The total average residence time of RP in the contactor is estimated to be 7 days, with a bulk average solids content of $1 \%$. The finely divided ore and biomass are then separated from the lixiviant, which contains the solubilized phosphate by means of a gravity clarification tank. It is assumed that separation can be performed using equipment similar in design to the final clarifiers used in wastewater treatment plants.

Lime will be added to the decanted lixiviant in a precipitation vessel. Dicalcium phosphate dihydrate crystals of a uniformly large size will form in the precipitation vessel as the mixture moves through this plug-flow vessel. Residence time is estimated to be 3 hours.

The solid crystals of dicalcium phosphate dihydrate will then be separated by sedimentation. A clarifier similar in design to the one used for separation of RP will be used. The product, a wet paste of precipitated dicalcium phosphate dihydrate, will be removed. The liquid, which contains a significant quantity of unmetabolized sugars, will flow to a unit process where calcium is removed.

Little work has been performed on the removal of calcium ion from the lixiviant. A precipitation process by neutralization with inorganic acids, or an ion exchange system may be employed. This issue will be addressed later, but for the purpose 


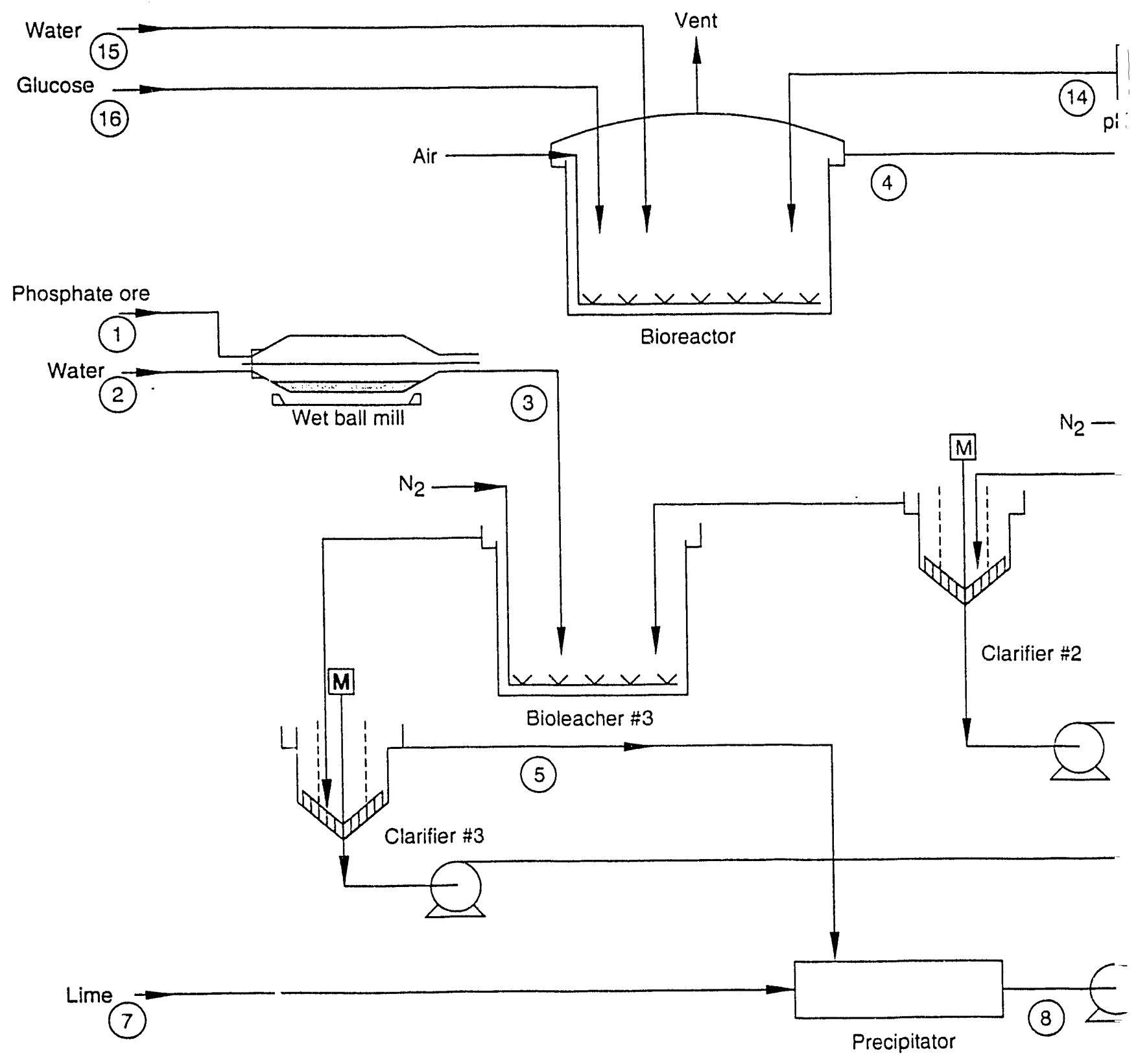

Figure 8. Process flow sheet for conceptual biosolubilization process. 

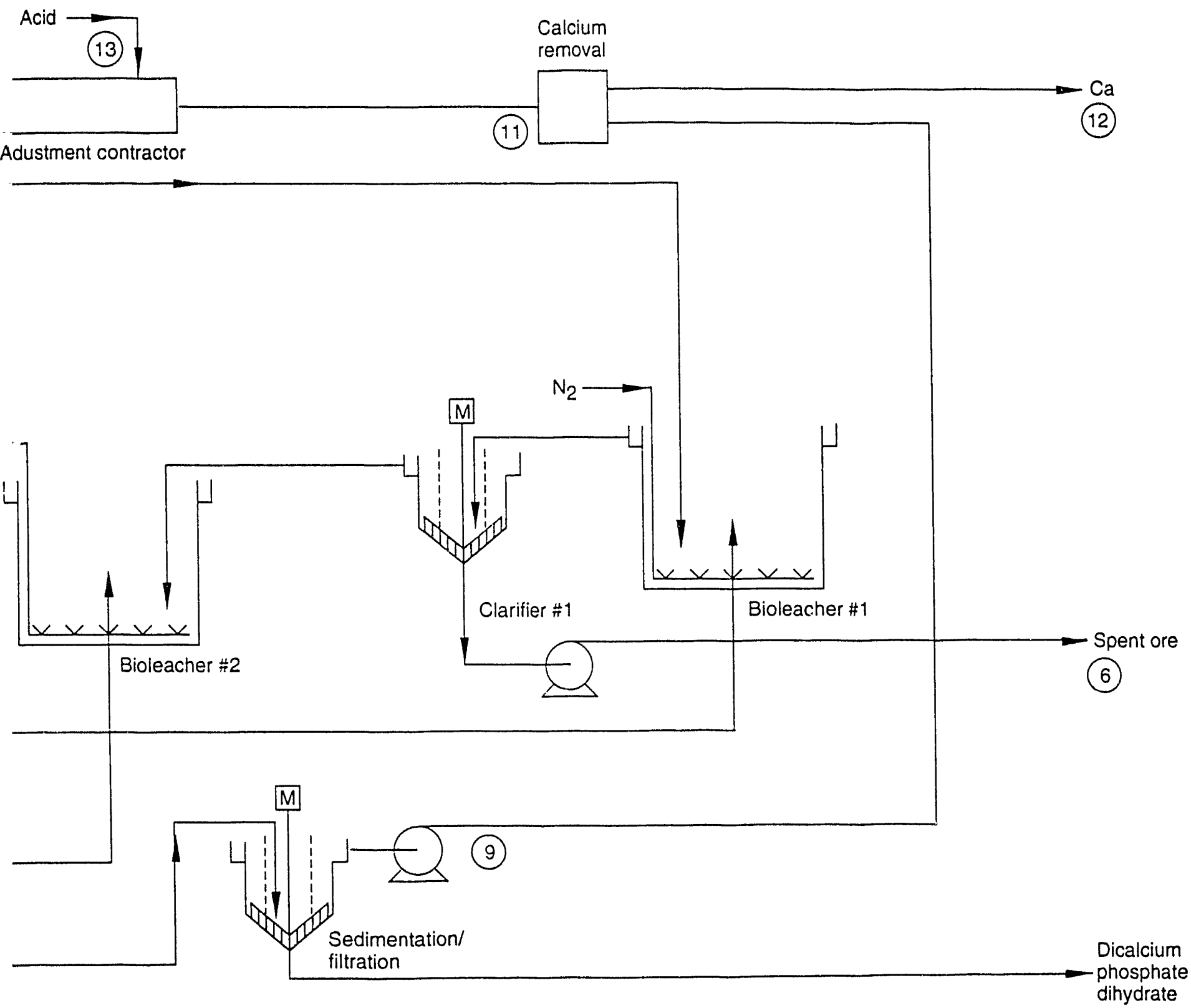
of the analysis will be considered an unknown separation system where calcium is removed from the recycled lixiviant.

The $\mathrm{pH}$ of the filtrate will be adjusted in a continuous flow contact mixer to a value that is optimal for growth of the bioleaching organism. The $\mathrm{pH}$ adjusted filtrate will then flow to the bioreactor wherein it will begin a new cycle.

\subsection{Mass Balance}

A mass balance of the bioprocess based on a $R P$ ore capacily of 2 million tons per year is presented in Table 6 . The mass balance represents flows based on the results of laboratory demonstrations of proof of principle. All assumptions used in the mass batance are noted as they relate to each stream number (see pp. 31-37). The stream numbers on the mass balance correspond to the stream numbers of the flow diagram of Figure 8.

The mass balance, which represents an ore throughput of about $10 \%$ of the United States current production capacity, reveals several important issues that must be addressed in furthering the bioprocess. The most pressing issue is that of the quantity of lixiviant that must be produced to process this quantity of ore. This quantity is by far the largest flow stream in the process and effectively determines the size of all the process equipment in the process except that of the ore sizing operation.

To date, the maximum concentration of soluble phosphate extracted by the lixiviant has been demonstrated to be about $192 \mathrm{mg} / \mathrm{L}$ of fresh lixiviant. This maximum concentration, when combined with the quantity of phosphate that must be solubilized, determines the total quantity of lixiviant that must be produced. This quantity of lixiviant significantly dwarfs that of any known biological producion process. ${ }^{17}$ The energy associated with moving this quantity of material would cause the process to become noneconomically feasible, since unit energy costs alone exceed unit product market value.
It is assumed that by calcium management and possibly genetic engineering of solubilizing microorganisms, that vast improvements can be made in the concentration of soluble phosphate. Therefore, it was determined that the process engineering analysis should be performed based on an assumption of the maximum concentration of phosphate that may be attainable after the microorganism has been optimized. A mass balance containing the estimated maximum attainable phosphate concentration of $19.2 \mathrm{~g} / \mathrm{L}$ ir spent lixiviant is presented in Table 7.

While the flows for the optimized process are still large, it is believed that they are realistic of what would be expected in a commercial phosphate ore processing plant.

\subsection{Equipment Sizing}

All equipment was sizeci off of a $24 \mathrm{~h} / \mathrm{d}$ operating cycle of $350 \mathrm{~d} / \mathrm{y}$. Because of the rough order 0 . "nagnitude nature of this analysis, only the major equipment capacities were evaluated. There was no attempt to adjust the size of equipment to accomm odate for process upsets and fluctuations that might be encountered. ${ }^{i 8}$

3.4.1 Ball Mill. A total of approximately 5,700 tons per day of RP must be processed. This can be accomplished using five continuous ball mills $12 \mathrm{ft} \times 12 \mathrm{ft}$. Each mill has a capacity of approximately 1,275 tons per day and will use approximately $1,300 \mathrm{Hp}$ each to operate. Sizing is based on literature values. ${ }^{19}$

3.4.2 Binreactor. A total of approximately 34,000 tons of lixiviant must be produced per day. This weight corresponds to a volume of $29.8 \mathrm{mil}-$ lion $\mathrm{L} / \mathrm{d}$. The total reactor volume is assumed to be equal to the daily utilization rate (hydraulic residence time is 1 day) and is, therefore, 28.3 million L. On this basis, four reactors, each containing 7.08 million $\mathrm{L}$ of reactor volume, operating in parallel will be used to produce the lixiviant.

The process equipment used for aerobic digestion in the treatment of wastewater probably 
Table 6. Mass balance for bioleaching of rock phosphate ore based on assumed process parameters supported by research data.

(All quantities in table below are in millions of tons per year)

\begin{tabular}{|c|c|c|c|c|c|c|c|c|}
\hline $\begin{array}{c}\text { Flow stream } \\
-> \\
\text { Species } \\
1 \\
\text { V } \\
\end{array}$ & 1 & 2 & 3 & 4 & 5 & 6 & 7 & 8 \\
\hline$R P$ ore & 2.000 & - & 2.000 & - & - & - & - & - \\
\hline Water & - & 0.740 & 0.740 & 1325. & 1325. & 1.129 & - & 1325. \\
\hline $\mathrm{PO}_{4}$ & - & - & - & - & 0.7639 & - & - & - \\
\hline $\mathrm{Ca}$ & - & - & - & - & 0.5078 & - & - & 0.8073 \\
\hline Glucose & - & - & - & 12.06 & 12.06 & - & - & 12.06 \\
\hline Inert & - & - & - & - & - & 1.733 & - & - \\
\hline Biomass & - & - & - & 1.005 & - & - & - & - \\
\hline Lime & - & - & - & - & - & - & 1.149 & - \\
\hline $\mathrm{CaHPO}_{4} \cdot 2 \mathrm{H}_{2} \mathrm{O}$ & - & - & - & - & - & - & - & 1.383 \\
\hline $\mathrm{H}_{2} \mathrm{SO}_{4}$ & - & - & 一 & - & - & - & - & - \\
\hline Total & 2.000 & 0.740 & 2.740 & 1,338 & 1,338 & 2.862 & 1.149 & 1,339 \\
\hline $\begin{array}{c}\text { Flow stream } \\
-> \\
\text { Species } \\
\text { I } \\
\text { V } \\
\end{array}$ & 9 & 10 & 11 & 12 & 13 & 14 & 15 & 16 \\
\hline RP ore & - & - & - & - & - & - & - & - \\
\hline Water & 1321. & 3.019 & 1321. & - & - & 1323. & 2.000 & - \\
\hline $\mathrm{PO}_{4}$ & - & - & - & - & - & - & - & - \\
\hline $\mathrm{Ca}$ & 0.8073 & - & - & 0.8073 & - & - & - & - \\
\hline Glucose & 12.06 & - & 12.06 & - & 一 & 12.06 & - & 1.340 \\
\hline Inert & - & - & - & - & - & - & - & - \\
\hline Biomass & - & - & - & - & - & - & - & - \\
\hline Lime & - & - & - & - & - & - & - & - \\
\hline $\mathrm{CaHPO}_{4} \cdot 2 \mathrm{H}_{2} \mathrm{O}$ & - & 1.383 & - & - & -- & - & - & - \\
\hline $\mathrm{H}_{2} \mathrm{SO}_{4}$ & - & - & - & 一 & 1.522 & - & - & - \\
\hline Total & 1,334 & 4.402 & 1,333 & 0.8073 & 1.522 & 1,335 & 2.000 & 1.340 \\
\hline
\end{tabular}


Table 7. Mass balance for bioleaching of rock phosphate ore: optimized process. (where process parameters are adjusted to those critical for process viability).

(All quantities in table below are in millions of tons per year)

\begin{tabular}{|c|c|c|c|c|c|c|c|c|}
\hline $\begin{array}{c}\text { Flow stream } \\
-> \\
\text { Species } \\
\text { I } \\
\text { V } \\
\end{array}$ & 1 & 2 & 3 & 4 & 5 & 6 & 7 & 8 \\
\hline $\mathrm{RP}$ ore & 2.000 & - & 2.000 & - & - & - & - & - \\
\hline Water & - & 0.740 & 0.740 & 11.09 & 10.81 & 0.9831 & - & 11.02 \\
\hline $\mathrm{PO}_{4}$ & - & - & - & - & 0.6995 & 0.06436 & - & - \\
\hline $\mathrm{Ca}$ & - & - & - & - & 0.4650 & 0.04279 & - & 0.7390 \\
\hline Glucose & - & - & - & 0.4595 & 0.4208 & 0.03871 & - & 0.4208 \\
\hline Inert & - & - & - & - & - & 1.073 & - & - \\
\hline Biomass & - & - & - & 0.3446 & - & - & - & - \\
\hline Lime & - & - & - & - & - & - & 1.052 & - \\
\hline $\mathrm{CaHPO}_{4} \cdot 2 \mathrm{H}_{2} \mathrm{O}$ & 一 & - & - & - & - & - & - & 1.267 \\
\hline $\mathrm{H}_{2} \mathrm{SO}_{4}$ & - & - & - & - & - & - & 一 & - \\
\hline Total & 2.000 & 0.7400 & 2.740 & 11.89 & 12.40 & 2.202 & 1.052 & 13.45 \\
\hline $\begin{array}{c}\text { Flow stream } \\
-> \\
\text { Species } \\
\text { I } \\
\text { V } \\
\end{array}$ & 9 & 10 & 11 & 12 & 13 & 14 & 15 & 16 \\
\hline RP ore & - & - & 一 & - & - & - & - & - \\
\hline Water & 8.254 & 2.766 & 8.254 & - & - & 9.647 & 1.145 & - \\
\hline $\mathrm{PO}_{4}$ & - & - & 一 & - & - & - & - & - \\
\hline $\mathrm{Ca}$ & 0.7390 & - & - & 0.7390 & - & - & - & - \\
\hline Glucose & 0.4208 & - & 0.4208 & - & - & 0.4208 & - & 0.4982 \\
\hline Inert & - & - & - & - & - & - & - & - \\
\hline Biomass & - & - & - & - & - & - & - & - \\
\hline Lime & - & - & - & - & 一 & - & - & - \\
\hline $\mathrm{CaHPO}_{4} \cdot 2 \mathrm{H}_{2} \mathrm{O}$ & - & 1.267 & - & - & - & - & - & - \\
\hline $\mathrm{H}_{2} \mathrm{SO}_{4}$ & - & - & - & - & 1.393 & - & - & - \\
\hline Total & 9.414 & 4.033 & 8.675 & 0.7390 & 1.393 & 10.07 & 1.145 & 0.4982 \\
\hline
\end{tabular}




\section{MASS BALANCE ASSUMPTIONS AND CALCULATIONS}

Note: Numbers with dots preceding them in CALCULATIONS column correspond to numbers in mass balance table.

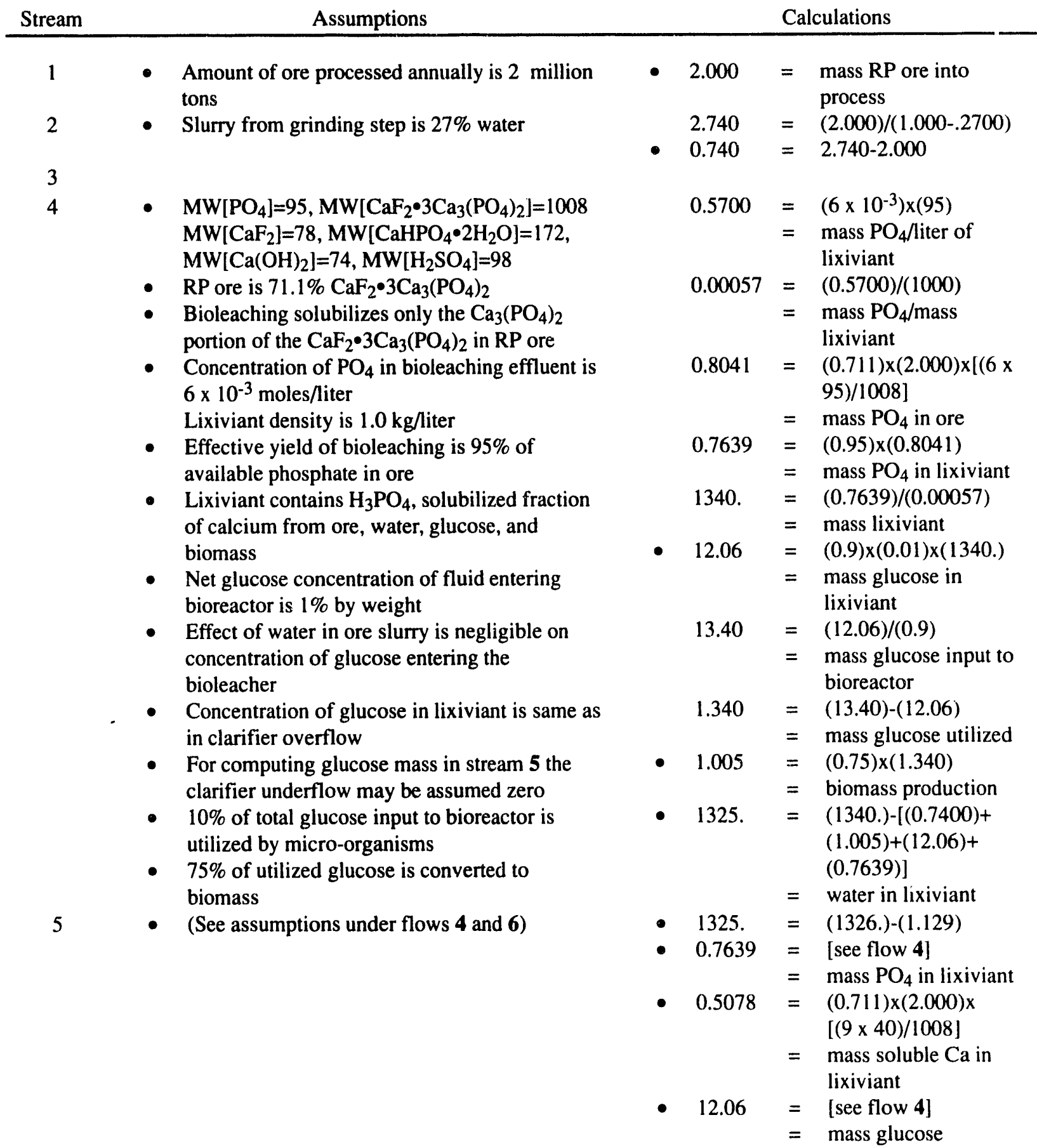


- Clarifier removes $100 \%$ of undissolved ore and all of biomass

- Clarifier underflow is $40 \%$ water

- Solids from clarifier include undissolved portion of RP ore and biomass

- $12 \mathrm{gm}$ lime precipitates $100 \%$ of $\mathrm{PO}_{4}$ in 14 liters of lixiviant @ 0.006 moles/liter $\mathrm{PO}_{4}$ concentration

- Total weight of precipitate in above reaction is 46 gm (Reference: R. D. Rogers report 1st Quarter 1991)

- Water mass includes $\mathrm{H}_{3} \mathrm{O}^{+}$, and $\mathrm{OH}^{-}$, excludes water of hydration in $\mathrm{CaHPO}_{4} \bullet 2 \mathrm{H}_{2} \mathrm{O}$

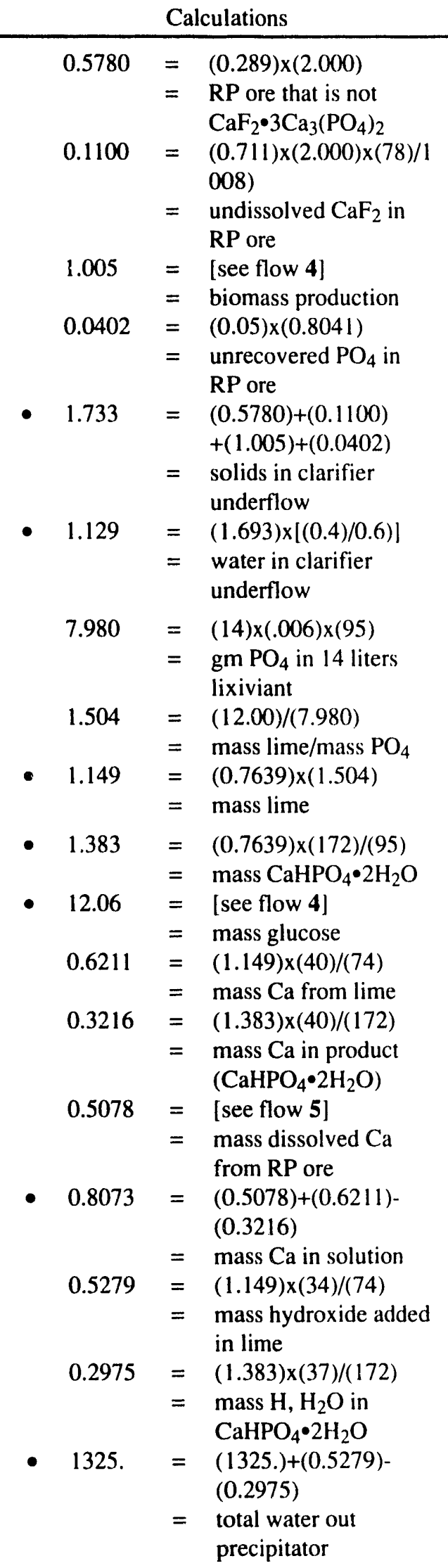




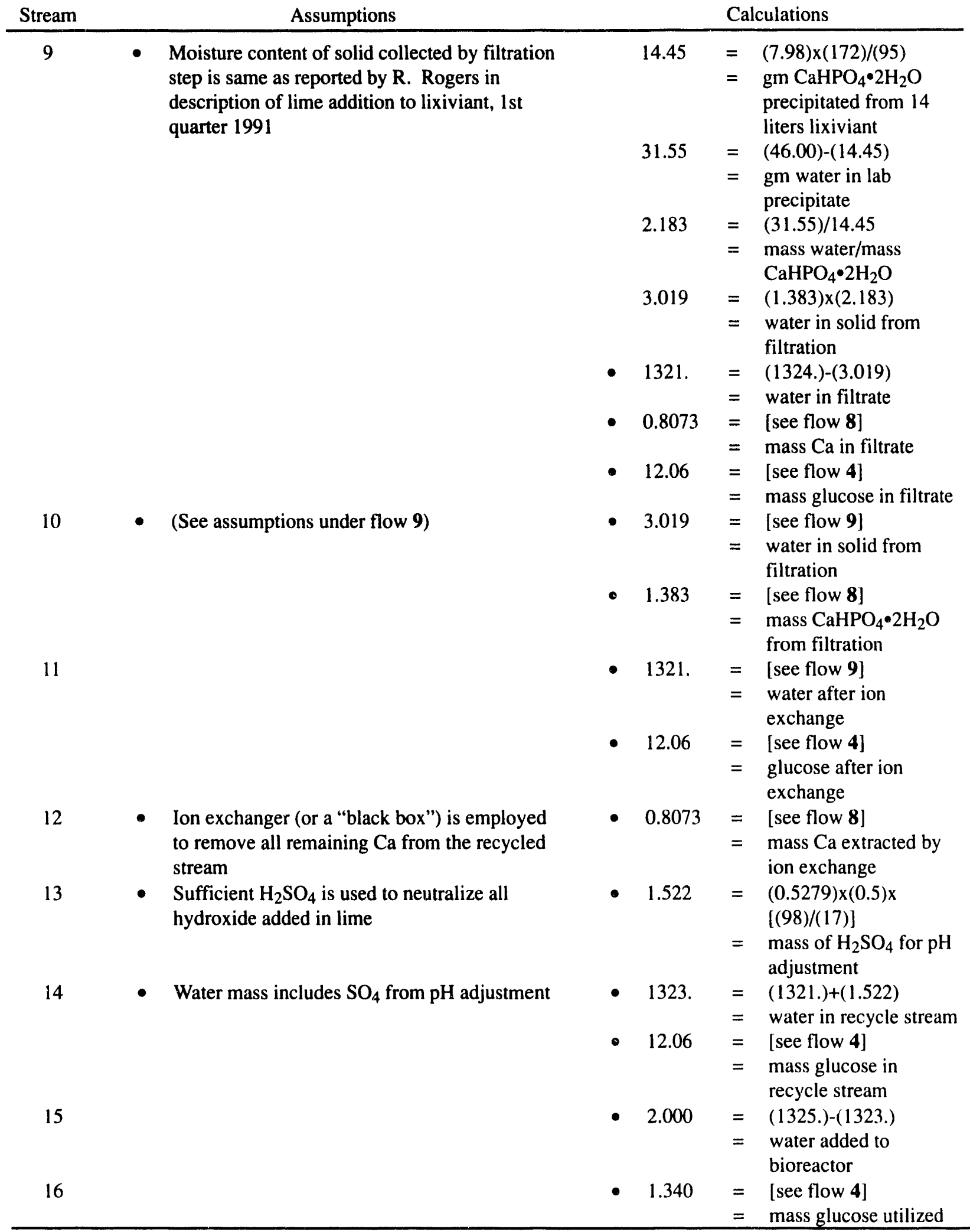


MASS BALANCE ASSUMPTIONS AND CALCULATIONS: OPTIMIZED PROCESS

Note: Numbers with dots preceding them in CALCULATIONS column correspond to numbers in mass balance table.

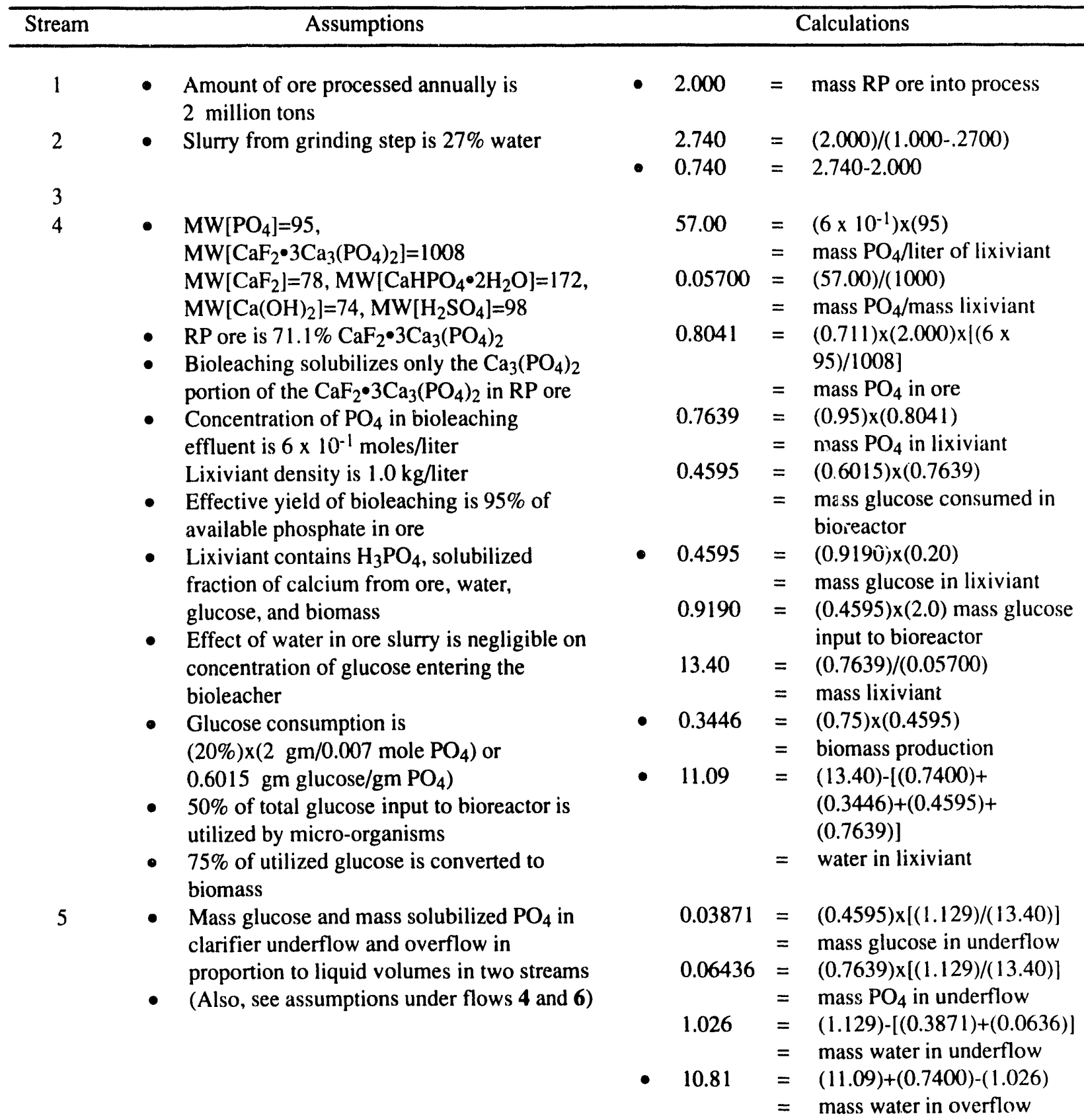




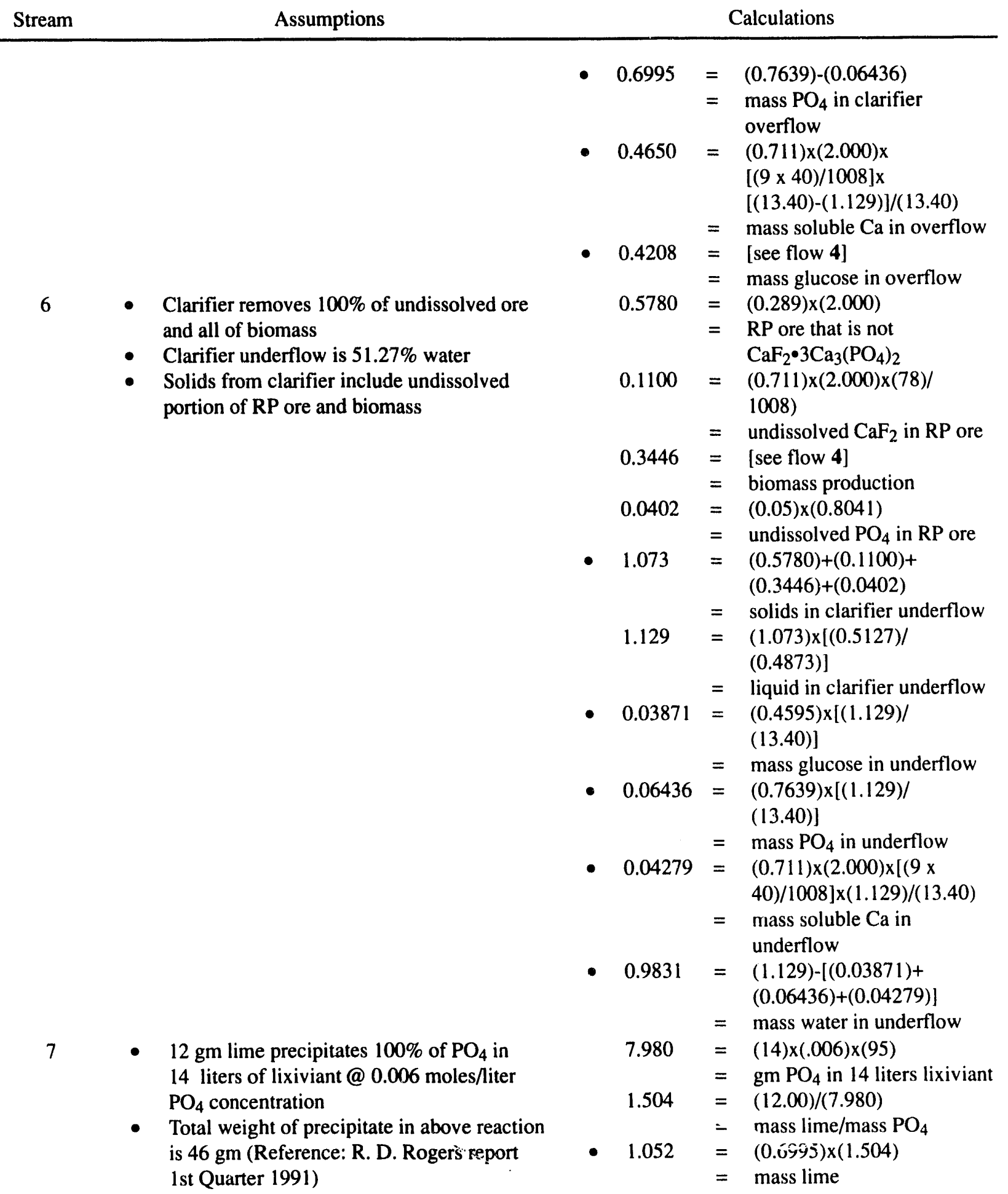


- Water mass includes $\mathrm{H}_{3} \mathrm{O}^{+}$, and $\mathrm{OH}^{-}$, excludes water of hydration in $\mathrm{CaHPO}_{4} \cdot 2 \mathrm{H}_{2} \mathrm{O}$ lixiviant, 1st quarter 1991
- $1.267=(0.6995) \times(172) /(95)$

$=$ mass $\mathrm{CaHPO}_{4} \cdot 2 \mathrm{H}_{2} \mathrm{O}$

- $0.4208=$ [see flow 5]

$=$ mass glucose

$0.5686=(1.052) \times(40) /(74)$

$=$ mass Ca from lime

$0.2946=(1.267) \times(40) /(172)$

$=$ mass $\mathrm{Ca}$ in product $\left(\mathrm{CaHPO}_{4} \cdot 2 \mathrm{H}_{2} \mathrm{O}\right)$

$0.4650=$ [see flow 5]

= mass dissolved Ca from RP ore

- $0.7390=(0.4650)+(0.5686)-$ (0.2946)

$=$ mass $\mathrm{Ca}$ in solution

$0.4833=(1.052) \times(34) /(74)$

$=$ mass hydroxide added in lime

$0.2725=(1.267) \times(37) /(172)$

$=\operatorname{mass} \mathrm{H}, \mathrm{H}_{2} \mathrm{O}$ in $\mathrm{CaHPO}_{4} \cdot 2 \mathrm{H}_{2} \mathrm{O} \bullet$

$11.02=(10.81)+(0.4833)-$ (0.2725)

$=$ total water out precipitator

$14.45=(7.98) \times(172) /(95)$

$=\operatorname{gm~CaHPO}{ }_{4} \cdot 2 \mathrm{H}_{2} \mathrm{O}$ precipitated from 14 liters lixiviant

R. Rogers in description of lime addition to

$31.55=(46.00)-(14.45)$

$=$ gm water in lab precipitate

$2.183=(31.55) / 14.45$

$=$ mass water $/$ mass

$\mathrm{CaHPO}_{4} \cdot 2 \mathrm{H}_{2} \mathrm{O}$

$2.766=(1.267) \times(2.183)$

$=$ water in solid from filtration

- $8.254=$ (11.02)-(2.766)

$=$ water in filtrate

- $0.7390=$ [see flow 8]

$=$ mass $\mathrm{Ca}$ in filtrate

- $0.4208=$ [see flow 4]

$=$ mass glucose in filtrate

- $2.766=$ [see flow 9]

$=$ water in solid from filtration

$=$ [see flow 8]

$=$ mass $\mathrm{CaHPO}_{4} \cdot 2 \mathrm{H}_{2} \mathrm{O}$ from filtration

- $8.254=$ [see flow 9]

$=$ water after ion exchange

- $0.4208=$ [see flow 4]

$=$ glucose after ion exchange 


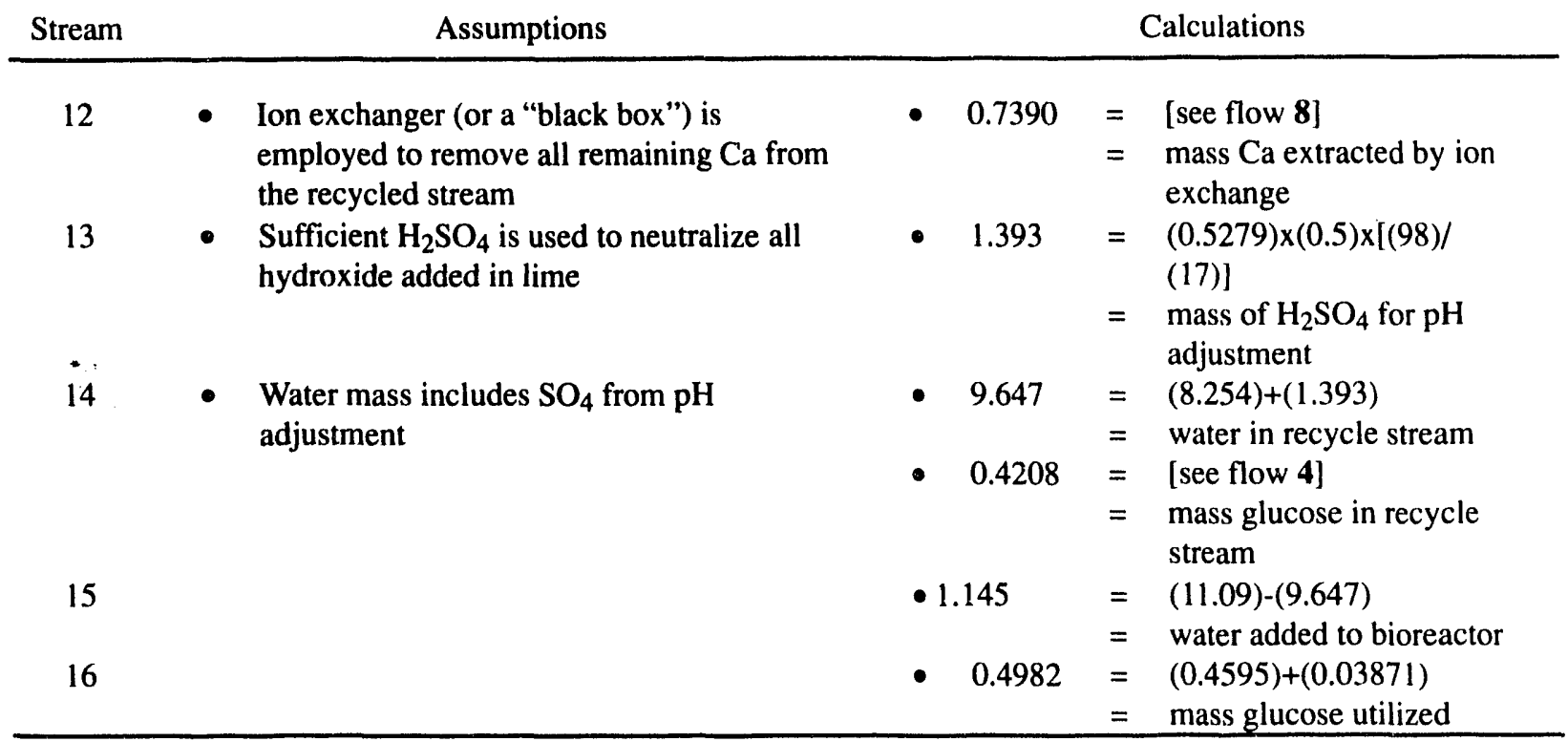

matches the needs for the bioreactor in terms of function. It is assumed that by properly enclosing an aerobic digester with a cover to prevent biological contamination that this equipment can be used as a bioreactor.

Fermentation process vats for manufacturing beer and ethanol were also considered as possible candidate units for the bioreactors, but the volume of lixiviant that must be produced would demand an incredible number of these vessels.

3.4.3 Contactor. The contactor must be sized based on the RP loading limit of the contactor and solids throughput. For this analysis it was assumed that a 7 day contact time with the lixiviant was required to extract the phosphate completely from the RP and that the solids loading of $\mathrm{RP}$ in the lixiviant was $1 \%$.

A 7 day in-process load of RP of approximately 39,900 tons dictates a total reactor volume of 3.48 billion L. It is presumed that each stage of the three-stage bioprocess will have the same volume and hence each stage must have the capacity for 1.16 billion $\mathrm{L}$ of in-process material. It is envisioned that several leaching lines of lesser capacity operated in parallel would probably be used instead of a single line. For this study it is presumed that six parallel leaching lines would be used, thus each bioleaching unit would have a capacity of 192 million L.

3.4.4 Bioleaching Clarifier. A clarifier is required for each bioleaching contactor, so for the plant under consideration, 18 clarifiers are required. Each clarifier must process approximately 82.1 million $L$ of in-process material daily. Based on sedimentation tank designs for wastewater treatment, ${ }^{20}$ a typical sedimentation tank has a capacity of roughly $40,700 \mathrm{~L} / \mathrm{m}^{2} \mathrm{~d}$. Approximately $2,050 \mathrm{~m}^{2}$ of surface is indicated. Based on a design recommendation of a retention time of $2 \mathrm{~h}$, the tank must be $4.3 \mathrm{~m}$ deep, giving a total volume of approximately 8.77 million $\mathrm{L}$.

3.4.5 Precipitator. It is envisioned that lime will automatically be meter fed to the phosphate rich lixiviant stream causing dicalcium phosphate dihydrate crystals to precipitate. It is estimated that a $3 \mathrm{~h}$ residence time is required to form uniform and easily separable crystals. As with the bioreactor lines, it is assumed that there are six parallel precipitator lines. Each line must process approximately 82.1 million $\mathrm{L} / \mathrm{d}$. Based on a $3 \mathrm{~h}$ residence time this corresponds to a precipitator volume of $116,000 \mathrm{~L}$.

3.4.6 Sedimentation/Filtration. It is assumed that sedimentation and filtration of the dicalcium phosphate dihydrate can be performed using essentially the same equipment as used for the 
separation of RP from lixiviant. Six sedimentation tanks with a capacity of 8.77 million L each would be required for separation of the product.

3.4.7 Calcium Removal. It is not known what process method may be used for separation of calcium from the recycled lixiviant flow stream, so this process step is not included in the evaluation, but it is recognized that calcium must be removed from the flow stream.

3.4.8 pH Adjustment Contactor. The adjustment of $\mathrm{pH}$ is routinely handled in the processing industries with either feedback or feed-forward control. Assuming a $5 \mathrm{~min}$ residence time and using six contactors, the volume of each contactor must be approximately $280,000 \mathrm{~L}$.

\subsection{Capital Cost Estimate}

Rough order of magnitude capital cost estimates have been prepared for the optimized bioprocess. The capital costs are based on the same premises and capacity as presented in the mass balance of Table 7 . The cost estimates are factored estimates based on purchased equipment costs. ${ }^{21,22}$ Purchased equipment costs were obtained from the '92 Richardson Rapid System Process Plant Construction Estimating Standards, Means Construction Cost Data, and Plant Design and Economics published information. The purchased equipment costs were multiplied by a factor to determine the total fixed capital investment. The fixed capital investment does not include working capital.

The factors used in determining total capital cost are based on information presented in Peters and Timmerhaus ${ }^{23}$ and are presented in Table 8. The total fixed capital investment for the 2 million ton per year ore capacity phosphate processing plant whose final product is dicalcium phosphate is estimated to be $\$ 318$ million. This amount does not include plant operating capital. A line item cost of major equipment is present in Table 9.
Table 8. Factors used to prepare total fixed capital cost estimate.

\begin{tabular}{lcc}
\hline \multicolumn{1}{c}{ Purchase equipment } & & $100 \%$ \\
\cline { 3 - 3 } Equipment installation & & 39 \\
Instrumentation/controls & & 13 \\
Piping & 31 \\
Electrical & 10 \\
Buildings & 47 \\
Yard improvements & 12 \\
Service facilities & 55 \\
Land & 6 \\
Engineering and & 32 \\
supervision & \\
Construction expenses & 34 \\
Total direct \& indirect costs & $379 \%$ \\
Contractor fee & 18 \\
Contingency & $\frac{65}{462 \%}$ \\
\hline Fixed capital investment & \\
\hline
\end{tabular}

\subsection{Energy Consumption}

Determining a complete energy balance for the proposed bioprocess plant is not practical based on the uncertainty of operation of the process equipment. Therefore, an effort has been made to identify the major consumers of energy in the bioprocess and relate them to the major consumers in the wet acid process.

The bioreactors aid contactors both require agitation to maintain intimate mixing. Based on an energy consumption for mixing of roughly $6.426 \mathrm{~J} / \mathrm{sec}-\mathrm{m}^{3}\left(0.8 / 1,000 \mathrm{Hp} / \mathrm{ft}^{3}\right)$, which is cited as average for a reactor of this type (see Reference 20), it is estimated that $98,000 \mathrm{hp}$ would be required to sustain mixing for the plant. This power consumption corresponds to an energy usage of $1.26 \times 10^{3} \mathrm{~J} / \mathrm{g}(543 \mathrm{Btu} / \mathrm{lb})$ ore processed.

As stated earlier, there are four filtering or separations operations in the bioprocess. It would be expected that as a minimum, the energy required for filtering would be at least four times as great 
Table 9. Optimized process equipment capital cost.

\begin{tabular}{lccrr}
\multicolumn{1}{c}{ Item } & Quantity & Size/capacity & $\begin{array}{c}\text { Unit cost } \\
(\$)\end{array}$ & \multicolumn{1}{c}{$\begin{array}{c}\text { Total cost } \\
(\$)\end{array}$} \\
\hline Ball mill & 5 & 1,275 ton/d & 204,900 & $1,025,000$ \\
Bioreactor & 4 & $7.08 \times 10^{6} 1$ & 388,000 & $1,552,000$ \\
Contactor & 18 & $1.97 \times 10^{8} 1$ & $2,816,000$ & $50,688,000$ \\
Clarifier & 18 & $8.77 \times 10^{6} 1$ & 605,000 & $10,890,000$ \\
Precipitator & 6 & $1.16 \times 10^{5} 1$ & 117,000 & 702,000 \\
Sedimentation tank & 6 & $8.77 \times 10^{6} 1$ & 605,000 & $3,630,000$ \\
Contactor & 6 & $2.8 \times 10^{5} 1$ & 28,000 & 168,000 \\
Total major equipment cost & & & & $68,655,000$ \\
\hline
\end{tabular}

as the wet oxidation process because of the 1,000 -fold increase in the volume of material that must be separated or filtered. ${ }^{24}$ Optimistically, a minimum separations cost of $1.12 \times 10^{3}$ $(516 \mathrm{Btu} / \mathrm{lb})$ of ore would be expected.

It is recognized that RP, water, and glucose streams must be sterile in order for contamination of the lixiviant to be prevented. Energy concerns related to this process have not been evaluated but could constitute a major energy consumption. Assuming that the ore temperature must be raised to $148^{\circ} \mathrm{C}\left(300^{\circ} \mathrm{F}\right)$ and that the specific heat of ore is $0.46 \mathrm{~J} / \mathrm{g}(0.2 \mathrm{Btu} / \mathrm{lb}-\mathrm{F})$, approximately $116 \mathrm{~J} / \mathrm{g}$ $(50 \mathrm{Btu} / \mathrm{lb})$ of ore would be required. It is estimated that at least as much energy would be required to sterilize the glucose stream.

It is estimated that recycled lixiviant must also be sterile, and may in fact present a significant energy consumption. As can be seen in the mass balance for the optimal conditions, 5 tons of recycled lixiviant must be sterilized for each ton of RP processed. Assuming that the lixiviant must be heated from ambient to $100^{\circ} \mathrm{C}\left(220^{\circ} \mathrm{F}\right)$ and that $90 \%$ of the energy can be recovered by heat exchange upon cooling, $168.5 \mathrm{~J} / \mathrm{g}$ of ore would be required for sterilizing the lixiviant.

The product from the proposed bioleaching plant is dicalcium phosphate and not phosphoric acid as in the wet acid plant. To compare the two processes, the thermodynamic energy level must be considered. For the quantity of product produced in this study from one pound of ore, a thermodynamic minimum of $300 \mathrm{Btu} / \mathrm{lb}$ of ore would be required to convert from dicalcium phosphate to phosphoric acid.

A refinec estimate of the energy consumption per pound of ore processed is presented in Table 10.

Table 10. Bioprocess unit operation energy consumption estimate.

\begin{tabular}{lrr}
\hline \multicolumn{1}{c}{ Unit operation } & $\begin{array}{c}\text { Net } \\
\text { J/g-ore }\end{array}$ & $\begin{array}{c}\text { Net } \\
\text { Btu/lb } \\
\text { ore }\end{array}$ \\
\hline Grinding & 5,397 & 2,322 \\
Mixing, & 1,262 & 543 \\
Bioreactor/contactors & & \\
Clarification & 2 & 1 \\
Precipitation & 2 & 1 \\
Filtration & 1,199 & 516 \\
pH Adjustment & 2 & 1 \\
Sterilization & 283 & 122 \\
Electric generation & 130 & 56 \\
Product energy & 697 & 300 \\
difference & & \\
Total & & \\
\hline
\end{tabular}


In light of the above estimate, it appears that bioleaching of RP may be competitive on an energy consumption basis with the wet acid process (see Table 11). This analysis shows that this bioprocess requires $379 \mathrm{~J} / \mathrm{g}(163 \mathrm{Btu} / \mathrm{lb})$ of ore to produce the wet acid product. Phosphoric acid generated from the bioprocess is expected to be of higher purity and of higher value in respect to the wet acid product. A better product comparison is made by relating the bioprocess product to that obtained by the oxidation (electric furnace)

Table 11. Energy use for wet acid process.

\begin{tabular}{lrr}
\hline Unit operation & $\begin{array}{c}\text { Net } \\
\text { J/g-ore }\end{array}$ & $\begin{array}{c}\text { Net } \\
\text { Btu/lb-ore }\end{array}$ \\
\hline Grinding & 5,397 & 2,322 \\
Digester/reactor & 300 & 129 \\
Adsorption tower & 0 & 0 \\
Filtration & 300 & 129 \\
Evaporation & 1,917 & 825 \\
Boiler & 555 & 239 \\
Electric & 130 & 56 \\
generation & & \\
& & \\
Total & 8,599 & 3,700 \\
\hline
\end{tabular}

method. Almost $9,100 \mathrm{~J} / \mathrm{g}(3,900 \mathrm{Btu} / \mathrm{lb})$ is conserved by the bioprocess (see Table 12). Based on the present phosphoric acid market, $70 \%$ of the market is served by the wet acid process, and 30\% is supplied by the oxidation method. Assuming that $70 \%$ of the dicalcium phosphate produced by the bioprocess is used for wet acid product and $30 \%$ for high grade phosphoric acid, approximately $2.7 \times 10^{12} \mathrm{Btu}$ in energy savings may be realizable for a 2 million ton per year plant.

Table 12. Energy use for the oxidation process.

\begin{tabular}{lrr}
\hline Unit operation & $\begin{array}{c}\text { Net } \\
\text { J/g-ore }\end{array}$ & $\begin{array}{c}\text { Net } \\
\text { Btu/lb-ore }\end{array}$ \\
\hline Sintering & 3,478 & 1,497 \\
Crushing & 21 & 9 \\
Mixing & 2 & 1 \\
Electric furnace & 7,854 & 3,380 \\
Combustion & 5,379 & 2,315 \\
Chamber & & \\
Precipitator & 9 & 4 \\
Electric & 1,264 & 544 \\
generation & & \\
Total & 18,007 & 7,750 \\
\hline
\end{tabular}




\section{RESEARCH RECOMMENDATIONS}

The consequences of reviewing research accomplishments to formulate a conceptual process for microbial phosphate solubilization are: (a) discovery of unanswered research questions, (b) identification of new avenues of research, and (c) identification of critical barriers that must be removed to make the process viable. In this research, analysis information is presented concerning observable aspects of the mechanism of phosphate solubilization by $P$. cepacia. Although, considerable progress has been made in uncovering the mechanism employed by $P$. cepacia, gaps in the understanding of the mechanism exist. Research studies have examined the process to characterize how unit operations function and to identify problems associated with either the microbe or RP. Solids separation and calcium management require additional study. Development of a conceptual bioprocess and associated engineering analysis is forced to make many assumptions concerning the operation of the bioprocess. Based on research results, this analysis finds that current liquid holding and handling requirements will make the bioprocess uneconomical. However, the analysis also suggests that a factor of 100 -fold increase in soluble phosphate concentration will reduce liquid requirements sufficiently to make the bioprocess competitive with the existing wet acid process. The engineering analysis also points to ore grinding and medium sterilization as energy intensive elements of the bioprocess.

The results of research studies performed during this project have answered many of the questions posed in Section 2.1. However, research questions still remain to be completely addressed. These questions include:

- Is the high concentration of hydrogen ion postulated to be present in the microbial intermembrane space responsibie for the observed enhanced solubilization?

- How do gluconic and 2-ketogluconic acid enhance RP solubilization when theoretical treatment suggests that they are undissociated at experimental $\mathrm{pH}$ values?

- Why does $200 \mathrm{mg} / \mathrm{L}$ soluble phosphate appear to be a limiting value when no calcium management is employed?

- Why does calcium ion concentration relate to soluble phosphate concentration? !s this a consequence of calcium-piiosphate solubility or a result of a calcium mediated microbial process?

- Why does the $\mathrm{pH}$ of lixivilant rise at low flow rates in air? Is the microbe using the organic acid as a nutrient?

- Can concentrations of $>2,000 \mathrm{ng} / \mathrm{L}$ be realized in a continuous process?

- Can mutants or genetically engineered organisms be created that have greatly enhanced phosphate solubilization?

The development of a conceptual process to treat RP has been performed based on many assumptions. This analysis shows clearly that the following are critical hurdles that research efforts need to address:

- The unoptimized process has final $200 \mathrm{mg} / \mathrm{L}$ phosphate levels and a solids density of $0.1 \%$. These low levels dictate tremendous liquids holding and moving requirements. These requirements cause the process design to be orders of magnitude larger than current bioprocessing technology. As a result, the fixed capital and variable costs calculated for this process are not economical.

- A more complete understanding of the relationships of microorganism propagation and life-cycle to classical engineering process parameters, such as temperature, nutrient concentration, $\mathrm{pH}$, and trace element concentration must be developed. 
- The process uses four separation steps, as compared to one for the wet acid process. Work needs to be performed on solid-liquid equilibrium constants to refine estimates on yield and capture efficiency.

- Grinding and media sterilization represent major energy requirements. Evaluation of ore size effects is needed to determine appropriate grind sice for the bioprocess. Enhancement of the organism's ability to grow relative to naturally occurring crganisms is needed to reduce sterilization requirements.

This assessment suggests that more fundamental research is required reiative to: (a) mechanivin of micróbial solubilization, (b) potential to perform genetic enhancement of the organism, (c) 'define methods for calcium management, and (d) obtain enginee-ing parameters for proposed separation unit operations. Research questions and critical hurdles are developed specifically for a process to separate phosphate from RP. A need to enhance scluble phosphate is generic to any material proposed to be processed by a phosphate solubilizing organism. Research activities that focus on soluble phosphate enhancement will benefit from a range of potential new bioprocessing technologies that rely on insoluble phosphate removal.

This assessment suggests that the current research effort be focused on a single objective: to enhance soluble pliosphate conceitrations in the process streams. The following research plan outline addresses this objective.

1. Mechanism of microbial solubilization

A. Refine proposed mechanism

1. Determine if the microbial membrane acts as a super aciu thai serves to initially release phosphate from RP.
2. Determine how calcium is removed from solution by organic acids.

3. Determine if microbial biomass acts as a hydrogen ion loaded cation exchange resin.

4. Determine if biomass attachment to RP particles is necessary for solut:ization to occur.

5. Explore genetic engineering as a possible means to enhance phosphate solubilization.

i. Understand genetic basis for gluconic acid production in terms of glucose utilization and hydrogen ion production.

ii. Determine how the organism is using carbon source, and how this can be improved.

iii. Develop super-solubilizer by genetic overproduction of hydrogen ion and organic acids.

iv. Provide a competitive advantage for growth, relative to wide type organisms.

\section{B. Process Research}

1. Evaluate continuous calcium ion removal by cation exchange resin with a goal of $20,000 \mathrm{mg} / \mathrm{L}$ sciluble phosphate in spent lixiviant.

2. Explore biologically produced polysaccharides as possible cation exchange resins.

3. Develop concentiation/scparation process for recovery of phosphate product. 
The engineering analysis suggests that research be focused on separation methodology for calcium removal and phosphate recovery. That research activity will be deferred.

This assessment has established a reasonable set of goals for microbial solubilization of phosphate. The most pressing of these is the production of solutions containing 100 times the present concentration of soluble phosphate.
Based on preliminary work reported herein, a factor of 10 enhancement can be provided through use of cation exchange resins to remove calcium ion. Additional genetic data indicates that supersolubilizer organisms are producible. With the additional research activities suggested above, an economic process that is transferable to industry may be developed not only for solubilization of phosphate from RP, but for any material containing insolubie phosphate. 


\section{SUMMARY}

This assessment reviews the progress made in understanding how a bacterium, $P$. cepacia, brings about phosphate solubilization from RP. Design and operational parameters have been characterized. Based on these results, an engineering analysis has been performed on a 2 million ton per year capacity conceptual bioprocess. An optimized process is suggested by this analysis to reduce plant water requirements. Using this optimized process, capital equipment costs are estimated to be $\$ 69$ million, and total fixed capital costs are estimated to be
$\$ 318$ million. Energy consumption estimates suggest that the bioprocess is comparable to the wet acid and will save approximately $2.7 \times 10^{12}$ Btu serving a market composed of $70 \%$ wet acid product and $30 \%$ oxidation product. Four critical hurdles to technology demonstration are suggested. A research plan has been developed to address the most significant of these barriers, enhancement of soluble phosphate. If all critical hurdles can be overcome, this new processing technology for phosphate recovery can be economical and conserve energy. 


\section{REFERENCES}

1. R. M. N. Kucey, H. H. Jansen, M. E. Leggett, "Microbially Mediated Increases in Plant Available Phosphorus," Advances in Agronomy, 42, 199, 1989.

2. H. A. Louw and D. M. Wedley, "A Study of Soil Bacteria Dissolving Certain Mineral Phosphate Fertilizers and Related Compounds," Journal of Applied Bacteriology 22, 227, 1959.

3. J. I. Sperber, "The Incidence of Apatite-Solubilizing Organisms in the Rhizosphere and Soil," Australian Journal of Agricultural Research 9, 788, 1958.

4. J. Kobus, 1962, "The Distribution of Microorganisms Mobilizing Phosphorus in Different Soils," Acta Microbiologica Polonica 11, 115.

5. S. M. Taha, A. A. Z. Mahmound, S. H. El-Damaty, and A. M. A. El-Hafea, "Activity of PhosphateDissolving Bacteria in Egyptian Soils," Plant and Soils 31, 129, 1969.

6. C. P. Singh, M. M. Mishra, and K. K. Kapoor, "Solubilization of Insoluble Phosphates by Mesophilic Fungi," Review of Ecological and Biological Sciences 19, 17, 1982.

7. R. M. N. Kucey, "Phosphate-Solubilizing Bacteria and Fungi in Various Cultivated and Virgin Alberta Soils," Canadian Journal of Soil Science, 63, 671, 1983.

8. H. P. Singh, R. P. Pareek, and T. A. Singh, "Solubilization of Rock Phosphate by Phosphate Solubilizers in Broth," Current Science, 53, 1212, 1984.

9. A. H. Goldstein, and S. T. Liu, "Molecular Cloning and Regulation of a Mineral Phosphate Solubilizing Gene from Erwinia herbicola," Biotechnology 5, 72, 1987.

10. H. Katznelson, and B. Bose, "Metabolic Activity and Phosphate-Dissolving Capability of Bacterial Isolates from Wheat Roots, Rhizosphere, and Non-Rhizosphere Soil," Canadian Journal of Microbiology, 5, 79, 1959.

11. P. Mitchell, "Vectorial Chemistry and the Molecular Mechanics of Chemosmotic Coupling: Power Transmission by Proticity," Biochemical Society Transactions 4, 398, 1976.

12. G. T. Austin, Shreve's Chemical Process Industries, 5th Ed., New York: McGraw-Hill Book Company, Inc., 1984.

13. A. D. Toy and E. N. Walsh, Phosphorous Chemistry in Everyday Living, 2nd Ed., Washington DC: American Chemical Society, 1987.

14. AIChE Authors, Sulfuric/Phosphoric Acid Plant Operations, A CEP Technical Manual, New York: American Institute for Chemical Engineers, 1982.

15. J. M. Smith and H. C. Van Ness, Introduction to Chemical Engineering Thermodynamics, 3rd Ed., New York: McGraw-Hill Book Company, Inc., 1959.

16. J. A. Kent, Riegel's Handbook of Industrial Chemistry, 8th Ed., New York: Van Nostrand Reinhold Company, 1983. 
17. J. Pinkava, Handbook of Laboratory Unit Operations for Chemists and Chemical Engineers, New York: Gordon and Breach Science Publishers, 1970.

18. S. M. Walas, Chemical Process Equipment Selection and Design, Boston: Butterworths-Heinemann, 1988.

19. R. H. Perry and C. H. Chilton, Chemical Engineer's Handbook, 5th Ed., New York: McGraw-Hill Book Company, Inc., 1973.

20. G. Tchobanoglous and F. L. Burton, Wastewater Engineering: Treatment, Disposal, and Reuse/Metcalf \& Eddy, Inc., 3rd Ed., New York: McGraw-Hill Book Company, Inc., 1991.

21. C. H. Chilton et al., Cost Engineering in the Process Industries, New York: McGraw-Hill Book Company, Inc., 1960

22. Chemical Engineering Magazine Editors, Modern Cost Engineering: Methods and Data, New York: McGraw-Hill Book Company, 1979.

23. M. S. Peters and K. D. Timmerhaus, Plant Design and Economics for Chemical Engineers, 4th Ed., New York: McGraw-Hill Book Company, Inc., 1991.

24. H. L. Brown et al., Energy Analysis of 108 Industrial Processes, prepared under US DOE Contract E(11-1)2862, Fairmont Press Edition, 1985. 

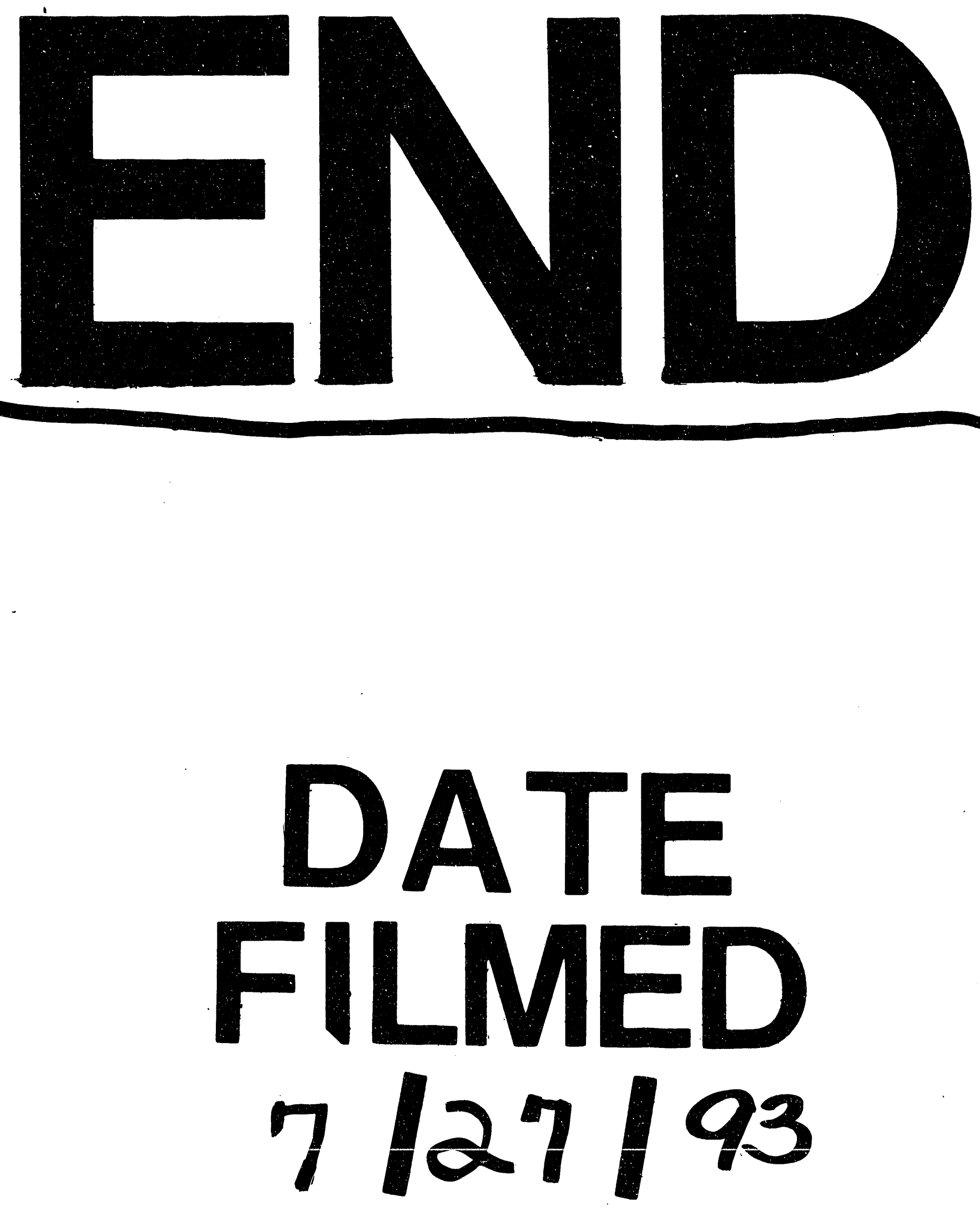
1 